\title{
Super-resolution Molecular Map of Basal Foot Reveals Novel Cilium in Airway
}

\section{Multiciliated Cells}

4 Quynh P.H. Nguyen ${ }^{1,2}$, Zhen Liu ${ }^{1,2}$, Rashmi Nanjundappa ${ }^{3}$, Alexandre Megherbi ${ }^{4}$, Nathalie

5 Delgehyr $^{4}$, Hong Ouyang ${ }^{5}$, Lorna Zlock ${ }^{6}$, Etienne Coyaud ${ }^{7}$, Estelle Laurent ${ }^{7}$, Sharon Dell ${ }^{8}$, Walter

6 Finkbeiner $^{6}$, Theo Moraes ${ }^{5}$, Brian Raught ${ }^{7}$, Kirk Czymmek $^{9}$, Alice Munier ${ }^{4}$, Moe R. Mahjoub ${ }^{10}$ 7 and Vito Mennella*1,2

9 1. Biochemistry Department, University of Toronto, Toronto, Canada.

10 2. Cell Biology Program, The Hospital for Sick Children, Toronto, Canada.

11 3. Department of Medicine, Nephrology Division, Washington University, St Louis, MO.

12 4. Cilia biology and neurogenesis, Institut de biologie de l'Ecole normale supérieure (IBENS), CNRS, 13 INSERM, PSL Université, Paris, France.

14 5. Translational Medicine Program, The Hospital for Sick Children, Toronto, Canada.

15 6. Department of Pathology, University of California San Francisco, San Francisco, CA, USA.

16 7. Princess Margaret Cancer Centre, University Health Network, Toronto, ON, Canada.

17 8. Child Health Evaluative Sciences, Program, The Hospital for Sick Children, Toronto, Canada.

18 9. Carl Zeiss Microscopy, Thornwood, New York, USA.

19 10. Department of Cell Biology and Physiology, Washington University, St Louis, MO.

$20 *$ Corresponding author. Email: mennellalaboratory@gmail.com

23 Keywords: Super-resolution Imaging, centrosome, basal bodies, appendages, airway, cilia, 24 ciliopathies, Primary Ciliary Dyskinesia, quantitative imaging, FIB-SEM 


\section{$33 \underline{\text { Abstract }}$}

34 Motile cilia are beating machines that play a critical role in airway defense. During airway

35 cell differentiation, hundreds of motile cilia are templated from basal bodies that extend a basal

36 foot, an appendage that links motile cilia together to ensure beating coordination. This assembly

37 has thus far escaped structural analysis because its size is below the resolution limit. Here, we

38 determine the molecular architecture and identify basal foot proteins using a super-resolution-

39 driven approach. Quantitative super-resolution image analysis shows that the basal foot is

40 organized in three main regions linked by elongated coiled-coil proteins. FIB-SEM tomography

41 and comparative super-resolution mapping of basal feet reveal that, among hundreds of motile

42 cilia of an airway cell, a hybrid cilium with features of primary and motile cilia is harbored. The

43 hybrid cilium is conserved in mammalian multiciliated cells and originates from parental

44 centrioles. We further demonstrate that this novel cilium is a signalling centre whose cellular

45 position is dependent on flow.

46

47

48

49

50

51

52

53

54 


\section{Introduction}

Motile cilia are beating machines that generate the propulsive force required for

59 mucociliary clearance, thereby protecting the airways from recurrent infections and environmental

60 pollutants ${ }^{1,2}$. To beat in coordination, motile cilia rely on the basal foot, a triangular structure

61 attached to the basal body on one end and to the microtubule cytoskeleton on the other, thereby

62 linking hundreds of motile cilia together in a network ${ }^{3,4,5}$. The hundreds of motile cilia on the

63 surface of an airway multiciliated cell are thought to be similar to each other and templated from

64 identical basal bodies each presenting at their base one basal foot ${ }^{6,7}$ pointing toward the direction

65 of ciliary beating ${ }^{8,9}$ - a phenomenon termed rotational polarity ${ }^{10,11}$.

In airway cells, loss of the basal foot results in disruption of the microtubule apical network,

67 irreversible disorientation of basal bodies and lack of motile cilia coordination ${ }^{4}$. In mice, loss of

68 the basal foot leads to respiratory manifestations indicative of Primary Ciliary Dyskinesia

$69(\mathrm{PCD})^{4,12}$, an autosomal recessive disease characterized by chronic airway infections, and

70 frequently associated with hearing loss, male infertility, hydrocephalus and heterotaxy, which can

71 lead to lung collapse and death in mid adulthood ${ }^{13,14,1,2,15,16}$. Despite the basal foot's critical role

72 in airway physiology and multiciliated cell function, its molecular organization remains to be

73 elucidated.

In cells protruding a primary cilium, the basal foot—along with centrosomal proximal end

75 proteins - keeps the primary cilium submerged by linking the basal body to the Golgi network

76 thereby avoiding ectopic Shh-signalling ${ }^{17,18}$. Differently from motile cilia, the basal foot of the

77 primary cilium is present in multiple copies per basal body and is thought to originate from nine

78 (or less depending on the cell type) subdistal appendages, mother centriole-associated structures

79 contributing to interphase microtubule organization ${ }^{21,20,8}$ (Fig.1a). In mammalian cells, subdistal

80 appendages appear in electron microscopy (EM) micrographs as thin, conical-shaped structures 
81 with a round tip connected to the centrosomal barrel by two microtubule triplets ${ }^{22,21,23,24}$. Less is

82 known about the basal foot structure and composition in primary cilia, and no consensus has been

83 reached on its nomenclature: this assembly has been named differently depending on the study and

84 cell type (e.g. satellite arms ${ }^{21}$, basal feet ${ }^{25}$ or subdistal appendages ${ }^{17}$ ).

Several proteins have been assigned to the basal foot and subdistal appendages in

86 mammalian cells through conventional fluorescence microscopy and immuno-EM (Ninein

$87(\mathrm{NIN})^{26}, \mathrm{ODF} 2 / \mathrm{Cenexin}^{4,27,28}, \mathrm{CC} 2 \mathrm{D} 2 \mathrm{~A}^{29}, \mathrm{CEP} 170^{30}$, Galactin-3 $^{3}, \varepsilon$-Tubulin $^{31}$, Centriolin

$88(\mathrm{CNTRL})^{32}$, Trichoplein $(\mathrm{TCHP})^{33}, \mathrm{CEP} 128^{17}, \mathrm{CEP} 19^{34}, \mathrm{CCDC}^{320}$ and $\mathrm{CCDC}^{35} 8^{35}$.

89 ODF2/Cenexin is a fibrillar protein related to the intermediate filament (IF) superfamily that plays

90 a critical role in basal foot assembly since lack of basal foot-specific ODF2/Cenexin isoform

91 results in loss of the entire structure ${ }^{4,5,12,36}$. ODF2/Cenexin interacts with TCHP, an IF-binding

92 protein implicated in the recruitment of NIN to subdistal appendages ${ }^{33}$. NIN and CEP170 have

93 been implicated in microtubule anchoring and nucleation functions ${ }^{38,39,40}$. Recently, CEP19 and

94 CC2D2A have been assigned to subdistal appendages with the latter shown to play a critical role

95 in their assembly ${ }^{34,29}$.

96 Despite the information has accumulated on individual proteins, to date a comprehensive

97 and quantitative view of the molecular architecture of the basal foot is still lacking. Moreover, it

98 remains unknown how the basal foot's organization changes in different cilia or in subdistal

99 appendages to accommodate its specific functions.

100 Here, we resolve the structure of the basal foot in cilia in situ using super-resolution

101 microscopy revealing an architecture composed of three regions linked by elongated proteins,

102 which is partly conserved in different types of cilia. Unexpectedly, our super-resolution analysis

103 reveals a novel "hybrid" cilium in multiciliated cells characterized by a basal body with multiple

104 basal feet. The hybrid cilium originates from parental centrioles and presents structural features of 
105 a motile cilium. Functional analysis using airway cells from healthy individuals and patients with

106 immotile cilia syndrome suggests that the hybrid cilium position is dependent on flow generated

107 by the surrounding motile cilia. Altogether, our data show that not all motile cilia are identical

108 beating machines in a multiciliated cell. Furthermore, they provide evidence of a novel sensing 109 mechanism in multiciliated epithelia.

$111 \underline{\text { Results }}$

112 Super-resolution Microscopy and BioID Reveals Structural Organization and Novel 113 Components of the Basal Foot

114 To determine the molecular architecture of the basal foot in situ, we first focused on primary 115 cilia from immortalized Retinal Pigment Epithelia 1 (hTERT-RPE1) cells, a cellular model 116 characterized by robust ciliation and homogenous ciliary structure. We reasoned that 3DSIM 117 microscopy resolution power $(\sim 125 \mathrm{~nm} \text { in } \mathrm{x} / \mathrm{y} \text { and } \sim 250 \mathrm{~nm} \text { in } \mathrm{z} \text { axis })^{41,42,43}$ was sufficient to assign 118 proteins to the basal foot and/or to other ciliary regions (Fig. 1a). To test this, we examined the 119 distribution of NIN, a basal foot protein reported to have different sub-populations at the basal 120 body $^{44}$. Using 3DSIM, we clearly distinguished three sub-populations of NIN: one at the proximal 121 end of the basal body, one at the daughter centriole, and a third at the basal foot, which extends 122 laterally at the distal end of the basal body (Fig. 1b). We then quantitatively mapped the position 123 of all reported basal foot/subdistal appendage proteins relative to the centre of the basal body 124 measured by polyglutamylated-Tubulin, a modification of centriolar microtubules that is a proxy 125 for the outer diameter of centrioles $(\sim 200 \mathrm{~nm} \text {; Fig. 1c })^{45}$. Since 3DSIM resolution is maximum in 126 the $\mathrm{x} / \mathrm{y}$ plane, in-plane end-on and side-views were selected for measurement from hundreds of 127 micrographs with basal foot proteins labeled with 488-conjugated secondary antibodies to ensure 128 highest resolution power (Fig. 1c, Sup. Fig. S1). 
Notably, 3DSIM mapping shows that basal foot proteins are clustered into spatially

130 separated regions (Fig. 1d, Table S1). NIN and CEP170 are the most distant from the centriole 131 center $(248 \pm 16 \mathrm{~nm}$ and $237 \pm 25 \mathrm{~nm}$, respectively), consistently with their association with 132 microtubules ${ }^{26,38,39}$. Therefore, this region was termed the microtubule-anchoring region or region 133 III. Most basal foot proteins are clustered with ODF2, a component critical for basal foot 134 assembly ${ }^{4,5}$ (ODF2: 155 $\pm 16 \mathrm{~nm}$; CEP128: 139 $\pm 15 \mathrm{~nm}$; CEP19: 166 $\pm 15 \mathrm{~nm}$; and CNTRL: $153 \pm 18$ $135 \mathrm{~nm}$; TCHP: $135 \pm 15 \mathrm{~nm}$; Galactin-3 shows a broad distribution centred around this region (185 \pm 36 $136 \mathrm{~nm})$. Since this intermediate region contains ODF2, it was termed the scaffolding region or region 137 II. Interestingly, our imaging map shows a gap where the basal body connects to the basal feet, a 138 region that was termed the basal body anchoring region or region I. Among the proteins previously 139 assigned to the basal foot/subdistal appendage, $\varepsilon$-tubulin, CCDC120, CCDC68 could not be 140 reliably detected at the basal foot with available commercial antibodies, while TCHP, a protein 141 thought to be associated only with subdistal appendages ${ }^{31,35}$, was located to the basal foot in 142 primary cilia. To correctly assign proteins to the basal foot, we then measured the position of basal 143 foot proteins along the axoneme relative to the proximal end of the basal body (Fig. 1c, e). As 144 expected, most basal foot proteins were distributed in the same axial region (209-284 nm), with 145 the exception of CC2D2A, whose c-termini was located significantly above the basal foot (333 \pm 22 $146 \mathrm{~nm}$ ) and below the transition zone labeled with RPGRIP1L, a bona fide transition zone protein that 147 is part of the Y-links $(393 \pm 90 \mathrm{~nm} \text {; Fig. 1e })^{46}$. This suggests that CC2D2A is located not 148 exclusively within the basal foot region. To ensure basal foot structural integrity, we hypothesized that some proteins must be 150 connecting different regions of this supramolecular assembly together as molecular linkers either 151 in the form of pearls on a string and/or elongated proteins ${ }^{47,48,49}$. Since most basal foot proteins 152 showed similar distribution variances, linkers were likely to be high-molecular weight, elongated 
153 coiled-coil proteins, similar to centrosomal proteins of the pericentriolar material ${ }^{47}$. We then used

154 antibodies and GFP-fusion proteins labeling different protein domains to identify their position

155 within the basal foot (Fig. 1f). Notably, CNTRL was found to link regions II and III by extending

156 over a distance of $\sim 75 \mathrm{~nm}$ (CNTRL C-Terminal Domain (CTD): 153 $\pm 18 \mathrm{~nm}$; GFP-CNTRL:

$157240 \pm 19$ nm; Fig. 1g). CEP128 also showed an extended organization, but not as far from the basal

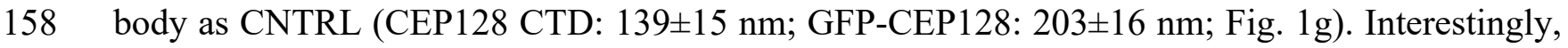

159 NIN also showed an elongated distribution looping back toward region II (Sup. Fig. S2, Sup. Table

160 S2). In contrast, CEP170 did not appear extended consistently with its lack of coiled-coil domains

161 (CEP170 CTD: 237 \pm 25 nm; Middle Domain (MD): $231 \pm 22 \mathrm{~nm}$; N-terminal Domain (NTD):

$162244 \pm 22 \mathrm{~nm}$, Fig. 1g). Altogether, our data rule out a model where a single basal foot component

163 spans the whole structure acting as a scaffold for the recruitment of other components. It shows

164 instead that the basal foot is organized in distinct structural regions: region III is the microtubule-

165 anchoring/nucleation region made of proteins CEP170 and NIN corresponding to the basal foot

166 cap; region II consists of the majority of known basal foot proteins (TCHP, CEP128, ODF2,

167 CEP19 and CNTRL) and region I anchors the basal foot to the basal body, though its composition

168 is not yet well characterized. Subdistal appendages show a similar architecture to the basal foot of

169 primary cilia, suggesting that their structure remains largely conserved during the transition from

170 centrioles to basal bodies in primary cilia despite the change in the number of appendages and/or

171 possible changes in composition (Sup. Fig. S3, Sup. Table S3).

Since our map showed few basal foot proteins in the region closer to the basal body, this

173 suggested that new basal foot proteins might have yet to be identified and if so, they should be

174 located in close proximity to CEP128, the coiled-coil protein nearest to the basal body. To test

175 this possibility, we mined BioID data from datasets that used BirA* fused to the N-terminus of

176 CEP128 (BirA*-CEP128), the furthest CEP128 domain from the basal body (Fig. 1f) ${ }^{34}$, and 
177 performed Bio-ID experiments using CEP128-BirA*, where BirA* is fused to C-terminus of

178 CEP128, the closest domain of CEP128 to the basal body (Fig. 1g). CEP128 proximity map

179 included many centrosomal, ciliary and satellite proteins as expected, but also components of

180 different cytoskeletal structures including actin and intermediate filaments. To identify novel

181 components of the basal foot, we then followed up on CEP112, a protein previously assigned to

182 the centrosome ${ }^{50}$ that is enriched in coiled-coil domains and was identified in BioID experiments

183 in close proximity to both centriolar marker CEP135 and to basal foot region II marker CNTRL.

184 Immunolabeling of CEP112 with two antibodies raised against different epitopes of the protein

185 showed a localization pattern consistent with that of a basal foot protein located close to the basal

186 body centre (CTD: $128 \pm 13 \mathrm{~nm}$; MD: $142 \pm 14 \mathrm{~nm}$ ), with a second population at the daughter

187 centriole (Fig. 1h, Sup. Fig. S4).

\section{Super-resolution Microscopy of the Basal Foot in Motile Cilia}

We next asked whether the architecture of the basal foot was conserved in motile cilia.

190 Since the basal foot plays an important structural role linking motile cilia together to ensure proper 191 beating coordination, it is likely organized differently than in primary cilia ${ }^{11,4,5}$. TEM micrographs

192 of basal foot from sections of human airway multiciliated cells suggest both structural similarities

193 and differences (Fig. 2a). The basal foot appears by EM as a conical structure $(\mathrm{h}=\sim 130 \mathrm{~nm}$ and

$194 \mathrm{~W}=\sim 200 \mathrm{~nm}$ ) attached to the basal body by three microtubule triplets with several electron-dense

195 regions, including a bulky domain at the tip, the basal foot cap ${ }^{3,21}$. Similarly to primary cilia, the

196 basal foot cap has a round structure with anchored microtubules (Fig. 2a, asterisk) and it appears

197 connected with the central region of the basal foot by fibrils (Fig. 2a, blue arrrowhead). Differently

198 from primary cilia, the basal foot is wrapped by two spherical structures symmetrically positioned

199 close to and on the side of the tip and it is connected to the basal body by arches originating from

200 three axonemal microtubules triplets (Fig. 2a, red arrowheads). 
To assign basal foot proteins in situ in motile cilia, we used POC1B a component of the basal body as a reference marker (Fig. 2 b $)^{51,52}$. Since in motile cilia there is only one basal foot per basal body, the pattern of basal foot proteins by 3DSIM appeared as a diffraction-limited spot, and not as a ring-pattern as observed in primary cilia (Fig. 1b, c). Taken together, the molecular map data show that basal foot molecular architecture is only partly conserved between motile and primary cilia (Fig. 2d, e, Sup. Table S4). NIN and CEP170 are located at the basal foot tip together with $\gamma$-Tubulin and NEDD1, proteins which are part of the $\gamma$ TuRC microtubule nucleating complex

53. The position of $\gamma$-Tubulin and NEDD1 was measurable only in motile cilia since basal bodies are largely devoid of Pericentriolar Material, the protein network surrounding the centriolar core ${ }^{54}$.

210 Region II components CEP128 (162 $\pm 25 \mathrm{~nm})$ and ODF2 (158 $\pm 16 \mathrm{~nm})$ in motile cilia showed 211 similar distances from the centriole wall as in primary cilia, while CNTRL is located further away 212 from the basal body centre $(180 \pm 23 \mathrm{~nm}$ and $153 \pm 18 \mathrm{~nm}$, respectively) suggesting a distinct 213 organization of this bridging protein in motile cilia. Notably, STORM microscopy shows that

214 CNTRL is distributed in two main populations at the basal foot, located on opposite side of its 215 longitudinal axis (Fig. 2f). Comparison of the measurements from EM micrographs with the ones 216 from super-resolution images suggests that CNTRL fluorescence is located where two electron217 dense spherical structures are detected in EM sections (distance of the basal body center to 218 spherical structures by EM: $190 \pm 15 \mathrm{~nm}$; CNTRL distance from basal body center by 3DSIM: $219180 \pm 23 \mathrm{~nm})$. In fully differentiated multiciliated cells, CEP112 was observed as a small arch on 220 one side of the basal body in close proximity to Cep128 ( $d=165 \pm 28 \mathrm{~nm}$, Fig. $2 \mathrm{~g})$ or a more closed 221 ring in cells that appear not completely mature suggesting a dynamic distribution of the protein 222 during differentiation (Sup. Fig. 5a). Cep19, on the other hand, forms a complete ring more similar 223 to distal appendages proteins throughout docking and motile cilia extension. Lastly, TCHP showed 224 a complex filamentous distribution that did not allow accurate measurements (Sup. Fig. S5). 
Altogether, our data show that basal foot architecture in primary and motile cilia is composed of modular regions that are largely conserved away from the basal body, while different in the basal body attachment region.

\section{Super-resolution Reveals a Novel Type of Cilium in Airways Multiciliated Cells} cilia (Fig. 1b and Fig. 2b). In human multiciliated cells, it was therefore surprising to observe a

235 of a basal body similar to the primary cilium one.

3DSIM and STORM micrographs from human multiciliated cells co-labeled with

237 antibodies recognizing basal foot (CNTRL, CEP128) and basal body (POC1B) proteins

238 demonstrated that the ring pattern resulted from a basal body with multiple basal feet and not from

239 multiple basal bodies clustering together as in the compound cilia, a membrane-delimited structure

240 made of multiple motile cilia clustered together and frequently found in airway cells after injury ${ }^{55}$

241 (Fig. 3a, c; Sup. Fig. S6). To further confirm its in vivo relevance and organization, we established

242 its presence in freshly isolated human upper airway cells (Fig. 3b) and in TEM micrographs (Fig.

243 3d). Furthermore, we then used 3DSIM to verify that an axoneme is emerging from it therefore

244 demonstrating that this special basal body templates a cilium (Fig. 3e).

\section{The Novel Cilium has Hybrid Features of Primary and Motile Cilia}


Movie 1,2) confirmed that the basal body templates a bona fide cilium and demonstrated that its axoneme contains a central pair similar to the surrounding motile cilia (Fig. 4a, b and Sup. Video 1-3). 3DSIM micrographs of airway multiciliated cells labeled with anti-radial spoke head (RSPH4A) and nexin-dynein regulatory complex (GAS8) antibodies further demonstrated that this special cilium harbors proteins specific for the ciliary beating machinery (Fig. 4d) ${ }^{56,57}$. Altogether, our data show that in human multiciliated cells of the airway, not all the cilia are identical; rather, a single cilium per cell on average presents hybrid features of primary and motile cilia.

Hybrid Cilium is Conserved in Different Mammalian Multiciliated Cells and Originates from

To determine if the hybrid cilium is conserved in other multiciliated cells and mammalian species, we examined multiciliated cells differentiated from progenitor basal cells isolated from

259 adult mouse tracheal and ependymal tissue (Fig. 5a, b). Notably, when using 3DSIM microscopy and TEM we observed a basal body surrounded by multiple basal feet in these multiciliated cells demonstrating that the hybrid cilium is present in multiple tissues in mice and humans. might be derived from the parental (mother) centriole, which first templates the primary cilium

264 present during the early stages of differentiation of airway multiciliated cells, and then is resorbed

265 before centriole amplification through the canonical and deuterosome pathway ${ }^{58,59,7}$. To first test

266 whether the mother and daughter centrosomal centrioles are retained in differentiated multiciliated 267 cells $^{58,60}$, we performed a pulse-chase experiment which allowed us to label differentially

268 centrosomal centrioles from newly formed basal bodies in mouse cultured ependymal cells 269 (Supplemental Fig. S7). Time-lapse monitoring of RFP-Cen1 centrosomal centrioles in cells from 270 Cen2-EGFP transgenic mice ${ }^{61}$ showed that centrosomal centrioles are retained within the newly 271 formed basal body patch (Fig. 5c) and are capable of growing cilia (Fig. 5d). To further test that 
272 they indeed provide a template for the hybrid cilium, we used Centrinone, a small molecule drug

273 blocking canonical centriole duplication by inhibiting Plk4, a kinase critical for the early stages of

274 centriole duplication ${ }^{62}$. As expected, basal cells isolated from mouse trachea treated with

275 Centrinone showed a reduction in the number of centrioles before airway cells differentiation into

276 an airway epithelia organoid model through Air Liquid Interphase (ALI) (d0) (Fig. 5e, f).

277 However, although Centrinone treatment during basal cell expansion in mouse cells does not

278 impact the number of multiciliated cells (Fig. 5e, f), it causes a reduction in hybrid cilia number in

279 terminally differentiated cells, suggesting that the hybrid cilium originates from parental centrioles

280 (Fig. 5g, h).

\section{Hybrid Cilium Is a Signaling Centre and Flow Sensor}

It has been previously shown that during multiciliated cells differentiation, motile cilia first generate fluid flow, then fine-tune their collective beating orientation within a cell to generate a

284 more effective fluid flow and mucociliary transport ${ }^{63,64,65}$. This observation suggested the

285 existence of a sensing mechanism converting mechanical forces into molecular signals required to

286 fine-tune basal body orientation at the cellular level ${ }^{66,67}$. We reasoned that if the hybrid cilium is

287 involved in a flow sensing mechanism, its position would be biased relative to the direction of

288 ciliary beating. To test this hypothesis, we then developed a MATLAB image analysis script that

289 located the position of the hybrid cilium in mature multiciliated cells relative to ciliary beating

290 direction measured by basal body-basal foot rotational polarity (Fig. 6a). To establish whether this

291 positional bias was dependent on fluid flow, we analyzed cells from three PCD patients with

292 independent loss of function mutations in outer dynein arm proteins (DNAH5 and DNAH11, Sup.

293 Table 5) critical for ciliary motility, but not basal body formation and docking. As expected, all

294 three PCD patient cells populations exhibited normal ciliation, but impaired beating, reduced basal

295 body rotational alignment and reduced number of aligned cells relative to healthy controls ${ }^{68,69,70}$ 
296 (Sup. Fig. S8). Surprisingly, when the position of the hybrid cilium was measured relative to motile

297 cilia beating direction, its position was biased toward the direction of ciliary beating in normal

298 cells, while in airway multiciliated cells from PCD patients its position was found more centered

299 in the cell, similarly to the position of centrosomes in cycling cells (Fig. 6b). To further confirm

300 the biased location of the hybrid cilium, we next assessed its position relative to the cell membrane

301 irrespective of motile cilia beating direction. Consistent with the previous analysis, in cells from

302 PCD patients the hybrid cilium was located closer to the cell center $(0.80<$ mean ratio $<0.85)$, while

303 in cells from healthy controls the hybrid cilium was found at a similar distance from the cell center

304 and the cell membrane (mean ratio of distances to the center vs membrane $=0.97)($ Fig. 6c).

305 Altogether, our data show that the hybrid cilium position is dependent on flow direction suggesting

306 that the hybrid cilium functions as a flow sensor.

To act as a sensor, the hybrid cilium must be competent for signalling. Since basal foot

308 protein CEP128 has been previously linked to TGF $\beta$ signalling in primary cilia ${ }^{71}$, we then

309 examined whether activated TGF $\beta$ receptors were found at the hybrid cilium consistently with a

310 sensing role. When airway multiciliated cells were labeled with an antibody recognizing

311 phosphorylated, activated TGF $\beta \mathrm{RI}^{72,73}$ phospho-TGF $\beta \mathrm{RI}$ was found enriched at the basal bodies

312 of airway primary and motile cilia throughout the differentiation process including at the base of

313 the hybrid cilium (Fig. 6d). Collectively, these results suggest that the hybrid cilium is not only a

314 fully functional motile cilium, but also a signalling antenna whose position is linked to the direction

315 of beating. 


\section{$\underline{\text { Discussion }}$}

\section{The Architecture of The Basal Foot Revealed by Super-resolution Microscopy}

Here, we present the super-resolution molecular map of the basal foot and show that the

322 basal foot has an architecture characterized by different protein regions linked by elongated coiled-

323 coil components, which bridge different parts of the basal foot. Our data show that the basal foot

324 in primary cilia and subdistal appendages share a conserved architecture, while basal foot in motile

325 cilia presents a more complex structure, with arches connecting basal foot to the basal body and

326 an overall more compact organization of region II and III relative to primary cilia. This

327 organization most likely reflects the different mechanical requirements that the basal foot in motile

328 cilia is subject to during ciliary beating. We initially hypothesized that the basal foot was built

329 upon an ODF2/Cenexin molecules infrastructure. ODF2, a highly insoluble, self-interacting

330 protein that forms a fibrillar structure is required for basal foot formation and is thought to have

331 an indirect association with microtubules ${ }^{27,74,17,33,5,4}$ and recruits CEP128, TCHP, CNTRL, NIN

332 and CEP170. However, our super-resolution map shows that ODF2 is rather a scaffold of region

333 (II), which is then required for assembly of region III.

STORM and 3DSIM super-resolution imaging of basal foot reveals that CNTRL plays a

335 role as a linker by connecting regions II and III along the longitudinal axis of the basal feet. In

336 addition, in motile cilia CTRLN laterally forms two domains that are symmetrically positioned on

337 opposite sides of the basal foot as a zipper suggesting that CTRLN provides a flexible architectural

338 element that can be adapted to build different assemblies.

340 basal boot to the basal body leading to the identification of CEP112 as a novel basal foot protein

341 in close proximity to CEP128 and providing through BioID mapping a candidate list for future 
342 studies. Last, the basal foot map clarifies the distribution of reported basal foot proteins such as

343 CC2D2A, TCHP and CEP19. We show that CC2D2A and TCHP are not classic basal foot

344 proteins, a notion supported by studies of the transition zone region ${ }^{75,76}$. Our map also shows that

345 CEP19 resides above the basal foot at a distance from the basal body consistent with the 346 measurements from Kanie et al. (Sup. Fig. S5, $d=334 \pm 38 \mathrm{~nm}$ (our data); $d=372.6 \pm 16.4 \mathrm{~nm}^{77}$ ). This

347 observation is supported by recent evidence suggesting that CEP19 forms a functional complex 348 with FOP and CEP350, distal appendage proteins required for an early step of ciliogenesis ${ }^{77,78,79}$.

A Novel Cilium in Airway Multiciliated Cells

Our data reveal the fate of parental centrioles in mature multiciliated cells. In airway cells,

351 during the early stages of differentiation-before Foxj1 expression-the mother centriole

352 templates a primary cilium that is subsequently re-adsorbed before centriole amplification ${ }^{7}$. After

353 this step, its role has remained mysterious. Here we show that parental (mother) centrioles

354 resurface to give rise to a hybrid cilium harbored among motile cilia. This hybrid cilium has

355 features of motile and primary cilia, that is multiple basal feet as a primary cilium and a central

356 pair apparatus and proteins required for ciliary beating as a motile cilium. Interestingly, the hybrid

357 cilium is evolutionarily conserved in mammalian multiciliated cells, but it has not yet been

358 identified in lower organisms such as xenopus pointing to species-specific differences.

The hybrid cilium is preferentially positioned toward the direction of ciliary beating. This

360 biased position is reminiscent of the primary cilium at the leading edge in the wound region in

361 vascular and bronchial smooth muscle cells, where it is thought to sense extra-cellular matrix

362 proteins and promote cell migration ${ }^{80,81}$. Since effective flow generated by beating motile cilia is

363 required to maintain the preferred position of the hybrid cilium this suggests that it senses flow

364 either directly or indirectly. The notion of a cilium with functional attributes of motile and sensory

365 cilia has been previously proposed in human tracheal epithelial and mouse oviduct epithelial 
366 cells ${ }^{82,83}$. Moreover, in lower organisms such hybrid motile-sensory cilia exist, but they have been

367 lost during the course of evolution in higher organisms ${ }^{84,85}$. Consistent with a role in sensing, the

368 parental basal body harbors phosphorylated TGF $\beta$ I receptors, providing a means for signal

369 amplification and compartmentalization around its location by possibly regulating relative

370 intensities. TGF $\beta$ is a complex signalling pathway integrated with multiple cellular processes,

371 whose downstream responses are cell and context dependent ${ }^{86}$. TGF $\beta$ signalling has been

372 previously associated with basal foot in primary cilia ${ }^{71,87}$, and in multiciliated epithelia it has been

373 shown to control motile cilia length independently from transcriptional programs responsible for

374 multiciliogenesis ${ }^{88}$. It is therefore possible that the parental basal body provides a signalling hub

375 in multiciliated cells to sense optimal/altered flow during differentiation or epithelial-to-

376 mesenchymal transition during tissue injury or inflammation, processes linked to TGF $\beta$ signalling

377 in airway cells ${ }^{83}$. Future studies are needed to address the downstream molecules and physiological

378 effects of TGF $\beta$ signalling through the parental basal body in the airways.

\section{$379 \quad$ Methods}

\section{Immortalized and Primary Cell Culture}

381 hTERT-RPE1 cell line (source: $\mathrm{ATC}^{\circledR}$ CRL-4000 ${ }^{\mathrm{TM}}$ ) was cultured in DMEM medium containing 382 10\% FBS. HEK293 Flp-In T-Rex cells were cultured in the DMEM medium containing 10\% FBS

383 (Tetracycline-free). For ciliation, RPE-1 and HEK293 cells were serum-starved with DMEM/F-

38412 media for 48-72 hours. Human primary nasal airway cells from healthy volunteers and PCD

385 patients were collected using a cytology brush by a nurse, with a protocol approved by Research

386 Ethics Board at the Hospital for Sick Children. Airway cells were then expanded, seeded on

387 transwells (Corning HTS Transwell-96 and -24 permeable support; $0.4 \mu \mathrm{m}$ pore size), and 388 differentiated for at least 21 days following Stem Cell Technologies protocols using PneumaCult- 
Ex and PneumaCult-ALI media. The media were supplemented with vancomycin, tobramycin,

390 gentamicin and antibiotic-antimycotic antibiotics.

\section{Transfection}

392 hTERT-RPE1 cells were transfected using Lipofectamine $3000 \mathrm{Kit}$ (Invitrogen) according to 393 manufacturer instruction. Cells were analyzed for downstream applications at 48-72 hours post 394 transfection (hpt).

\section{Cloning and Plasmids}

396 Please refer to Supplemental materials (Table S6) for a list of plasmids and primers used in this 397 study.

398 Antibodies

399 Please refer to Supplemental materials (Table S7) for a list of antibodies used in this study.

\section{$400 \quad$ Immunofluorescence}

401 RPE-1 cells were fixed on coverslips, and human nasal and mouse tracheal multiciliated cells from 402 ALI cultures were directly fixed on transwell filters with either methanol $\left(20\right.$ min at $\left.-20{ }^{\circ} \mathrm{C}\right)$ or 4 $403 \%$ Paraformaldehyde (PFA; $10 \mathrm{~min}$ at RT). For PFA fixation, cells were subsequently reduced 404 with $0.1 \%$ Sodium Borohydride for 7 minutes, then permeabilized with $0.2 \%$ Triton X-100 for 25 405 minutes. Cells were blocked using 5\% FBS-containing PBS, incubated with primary antibodies 406 for either 1 hour (RT) or overnight $\left(4{ }^{0} \mathrm{C}\right)$, and then secondary antibodies conjugated with 407 Alexafluor -405, -488, -555 and -647 nm (Thermo Fisher Scientific). When appropriate, cells were 408 stained with directly labeled primary antibodies (prepared using APEX Antibody Labelling Kit, 409 Thermo Fisher Scientific and Mix-n-Stain Antibody Labeling Kit, Sigma-Alrich). Cells were 410 nuclei stained with HOESCHT33342. 


\section{Super-resolution Imaging}

412 3DSIM data was collected using ELYRA PS.1 (Carl Zeiss Microscopy) with a Plan-Apochromat

$41363 x$ or $100 x / 1.4$ Oil immersion objective lens with an additional 1.6x optovar. An Andor iXon

414885 EMCCD camera was used to acquire images with $101 \mathrm{~nm} /$ pixel z-stack intervals over a 5-10

$415 \mu \mathrm{m}$ thickness. For each image field, grid excitation patterns were collected for five phases and

416 three rotation angles $\left(-75^{\circ} ;-15^{\circ},+45^{\circ}\right)$. The raw data was reconstructed and channel aligned

417 using SIM module of ZEN Black Software (version 8.1). 2D-STORM data was collected using

418 PALM mode in ELYRA PS.1 (Carl Zeiss Microscopy) with a Plan-Apochromat 63x or 100x/1.4

419 Oil immersion objective lens with an additional 1.6x optovar. An Andor iXon 885 EMCCD

420 camera was used to acquire images using TIRF mode. Lasers of wavelength $647 \mathrm{~nm}$ and $405 \mathrm{~nm}$

421 (if necessary) were used to activate the fluorophore. Raw data was reconstructed using PALM

422 module of Zen Black Software (version 8.1), with the account for overlapping molecules.

423 Reconstructed data was further processed for drift correction and binning using home-written

424 MATLAB script (can be accessed via the following link:

425 https://drive.google.com/open?id=11fuWn7kmZ-loCn79CKChJI5FeMme0fDU).

\section{Transmission Electron Microscopy (TEM)}

427 ALI filters of fully differentiated human nasal multiciliated cells were fixed in $2 \%$ glutaraldehyde 428 in $0.1 \mathrm{M}$ sodium cacodylate buffer. Samples were rinsed in $0.1 \mathrm{M}$ sodium cacodylate buffer with

$4290.2 \mathrm{M}$ sucrose, post-fixed in $1 \% \mathrm{OsO}_{4}$ in $0.1 \mathrm{M}$ sodium cacodylate buffer, dehydrated in a graded

430 ethanol series $(70 \%, 90 \%, 3 X 100 \%)$, infiltrated with propylene oxide, and embedded in Quetol-

431 Spurr resin. Serial sections (90 nm-thickness) were cut on a Leica Ultracut ultramicrotome, stained 432 with uranyl acetate and lead citrate, and imaged in a FEI Tecnai 20 TEM. 


\section{Focused Ion Beam Scanning Electron Microscopy (FIB-SEM)}

434 ALI filters of fully differentiated human nasal multiciliated cells were fixed in $2.5 \%$

435 glutaraldehyde and $0.05 \%$ malachite green oxalate in $0.1 \mathrm{M}$ sodium cacodylate buffer, rinsed in

$436 \quad 0.1 \mathrm{M}$ sodium cacodylate buffer, post-fixed in $0.8 \%$ potassium ferrocyanide and $1 \% \mathrm{OsO}_{4}$ in $0.1 \mathrm{M}$

437 sodium cacodylate buffer. The samples were treated with $1 \%$ tannic acid, stained with $0.5 \%$ uranyl

438 acetate, followed by dehydration in a graded acetone series $(25 \%, 50 \%, 75 \%, 95 \%$ and $100 \%)$,

439 and embedded in resin. Resin formulation: 18.2\% Araldite M (Sigma-Aldrich), 22.7\% Epon 812

440 (Sigma-Aldrich), 54.5\% Hardener DDSA (Sigma-Aldrich) and 4.5\% DMP-30 (Sigma-Aldrich).

441 FIB-SEM imaging for Sup. Movie 1,2 was performed as described below. Sample blocks for

442 analysis by FIB-SEM were trimmed and mounted on a $45^{\circ}$ pre-titled SEM stub and coated with a

443 4-nm layer of Pt to enhance electrical conductivity. Milling of serial sections and imaging of block

444 face after each Z-slice was carried out with the FEI Helios Nanolab 660 DualBeam using Auto

445 Slice \& View G3 ver 1.5.3 software (FEI Company, Hillsboro, OR USA). A block was first imaged

446 to determine the orientation relationship between the block face of ion and electron beams. A

447 protective carbon layer $50 \mu \mathrm{m}$ long, $8 \mu \mathrm{m}$ wide and $2 \mu \mathrm{m}$ thick was deposited on the surface of the

448 region of interest to protect the resin volume from ion beam damage and correct for stage and/or

449 specimen drift, i.e., perpendicular to the image face of the volume to be milled. Trenches on both

450 sides of the region of interest were created to minimize re-deposition during automated milling

451 and imaging. Imaging fiducials were generated for both ion and electron beam imaging and were

452 used to dynamically correct for drift in the $\mathrm{x}$ - and y-directions by applying appropriate SEM beam

453 shifts. Ion beam milling was performed at an accelerating voltage $30 \mathrm{kV}$ and beam current of 9.3

$454 \mathrm{nA}$, stage tilt of $9^{\circ}$, and working distance of $4 \mathrm{~mm}$. With each milling step, $10 \mathrm{~nm}$ thickness of the

455 material was removed. Each newly milled block face was imaged with the through-the-lens

456 detector for backscattered electrons (TLD-BSE) at an accelerating voltage of $2 \mathrm{kV}$, beam current 
457 of $0.4 \mathrm{nA}$, stage tilt of $47^{\circ}$, and working distance of $3 \mathrm{~mm}$. The pixel resolution was $10.3 \mathrm{~nm}$ with

458 a dwell time of $30 \mu$ s. Pixel dimensions of the recorded image were 1536 x 1024 pixels. Seven

459 hundred and forty-three images were collected and the images contrast inversed. Visualization and

460 direct 3-D volume rendering of the acquired dataset was performed with Amira 6.0.1 (FEI

461 Company, Hillsboro, OR USA). FIB-SEM imaging for Sup. Movie 3 was performed as describe

462 previously ${ }^{89}$.

\section{Western Blot}

464 Total cell lysates were collected using RIPA lysis buffer (Pierce, Thermo Fisher Scientific) freshly 465 added with protease inhibitor (Roche, Sigma-Aldrich). Lysates were loaded on 4-12 or 8\% Bis-

466 Tris Plus gels. Proteins were transferred to a nitrocellulose membrane and blocked using 5\% Skim-

467 milk in TBST. Protein blots were sequentially incubated with primary and HRP-conjugated 468 secondary antibodies diluted in 5\% BSA in TBST. Blots were developed using the Novex ECL 469 Chemiluminescent Substrate Kit (Invitrogen).

\section{$470 \quad$ Bio-ID Assay}

471 HEK293 Flp-In T-Rex cells were first co-transfected with the pcDNA5/FRT/TO CEP128-FLAG472 BirA* plasmid and Flp Recombinase Expression plasmid pOG44 (1:20 ratio) and selected for 473 stable expression with Hygromycin B and Blasticidin. Stable CEP128-FLAG-BirA* HEK293 Flp-

474 In T-Rex cell line was induced for BirA expression and biotinylated for $24 \mathrm{hrs}$ with $1 \mu \mathrm{g} / \mathrm{ml}$ 475 tetracycline and $50 \mu \mathrm{M}$ biotin. For ciliation experiments, cells were serum-starved to for 72 hrs. 476 Cells were then collected and processed for Bio-ID and FLAG Immunoprecipitation (IP) 477 experiments as described previously ${ }^{90}$.

\section{MTEC and ependymal cell experiments}


479 Mouse tracheal epithelia cell (MTEC) cultures were established as previously described ${ }^{91,92}$.

480 Briefly, C57BL/6 mice were sacrificed at 2-4 months of age, trachea were excised, opened

481 longitudinally to expose the lumen, and placed in $1.5 \mathrm{mg} / \mathrm{mL}$ Pronase E in DMEM/F12 medium

482 (Life Technologies) at $4^{\circ} \mathrm{C}$ overnight. Tracheal epithelial cells were dislodged by gentle agitation

483 and collected in DMEM/F12 with $10 \%$ FBS. After centrifugation, cells were treated with 0.5

$484 \mathrm{mg} / \mathrm{mL}$ DNase I for $5 \mathrm{~min}$ on ice and centrifuged at $4^{\circ} \mathrm{C}$ for $10 \mathrm{~min}$ at $400 \mathrm{~g}$. Cells were

485 resuspended in DMEM/F12 with $10 \% \mathrm{FBS}$ and plated in a tissue culture dish for $5 \mathrm{~h}$ at $37^{\circ} \mathrm{C}$ with

$4865 \% \mathrm{CO}_{2}$ to adhere contaminating fibroblasts. Non-adhered cells were then collected, concentrated

487 by centrifugation, resuspended in an appropriate volume of mTEC-Plus medium ${ }^{92}$, and seeded

488 onto Transwell-Clear permeable filter supports (Corning).

489 To eliminate parental centrioles, cells were incubated in the presence of $1 \mu \mathrm{M}$ Centrinone $\mathrm{A}^{62}$ for

4906 days. Air-liquid interface (ALI) was established 2 days after cells reached confluence by feeding

491 mTEC-Serum-Free medium ${ }^{92}$ only in the lower chamber. Cells were cultured at $37^{\circ} \mathrm{C}$ with $5 \%$

$492 \mathrm{CO}_{2}$, and media replaced every $2 \mathrm{~d}$, and fixed on the indicated days. All chemicals were obtained

493 from Sigma Aldrich unless otherwise indicated. Media were supplemented with $100 \mathrm{U} / \mathrm{mL}$

494 penicillin, $100 \mathrm{mg} / \mathrm{mL}$ streptomycin, and $0.25 \mathrm{mg} / \mathrm{mL}$ Fungizone (all obtained from Life

495 Technologies).

496 For ependymal cell culturing, all animal studies were performed in accordance with the guidelines

497 of the European Community and French Ministry of Agriculture and were approved by the Ethic

498 comity Charles Darwin (C2EA-05) and "Direction départementale de la protection des populations

499 de Paris", (Approval number Ce5/2012/107; APAFiS \#9343). The mouse strain, Cen2-GFP (CB6-

500 Tg (CAG-EGFP/CETN2)3-4Jgg/J, The Jackson Laboratory), has already been described ${ }^{61}$. For in

501 vivo analysis, animals used were homozygous for the Cen2-GFP. Lateral walls of the lateral brain

502 ventricles were dissected as previously explained ${ }^{93}$. The tissue was treated with $0.1 \%$ triton in 
BRB80 (80 mM K-Pipes pH6.8; $1 \mathrm{mM} \mathrm{MgCl2;} 1 \mathrm{mM}$ Na-EGTA) for 1 min prior to fixation and

504 fixed in methanol at $-20^{\circ} \mathrm{C}$ for $10 \mathrm{~min}$. Saturation and antibody incubations were performed in

505 PBS containing 10\% FBS and 0.1\% triton. Primary antibodies (CNTRL (monoclonal mouse from

506 Santa Cruz) and CEP164) were incubated overnight $\left(4^{\circ} \mathrm{C}\right)$. Secondary antibodies conjugated with

507 Alexa Fluor -555 and -647 were incubated for $1 \mathrm{~h}$.

508 For in vitro pulse-chase experiments, cultures were performed as previously described.

509 Transfection of ependymal cell progenitors was performed at $80 \%$ of confluency during the

510 proliferation phase with a CMV-TagRFP-Cen1 plasmid (gift from Xavier Morin, ENS, Paris),

511 which codes for human centrin 1 fused to TagRFP under the control of a CMV promoter, using

512 jetPRIME Polyplus kit. Cells (in $25 \mathrm{~cm}^{3}$ flask) were transfected with a mix of $0.75 \mu \mathrm{g}$ of DNA,

$513300 \mu \mathrm{L}$ of jetPRIME Buffer and $1.5 \mu \mathrm{L}$ of jetPRIME transfection reagent in $3 \mathrm{~mL}$ of fresh complete

514 medium (DMEM-Glutamax (Invitrogen) containing 10\% FBS and 1\% Penicillin/Streptomycin).

515 After 4 hours at $37^{\circ} \mathrm{C}$ in $5 \% \mathrm{CO} 2$ incubator, the medium was renewed. One day after proliferation,

516 cells were shaken at $250 \mathrm{rpm}$ overnight. Cells were plated on coverslips or Labtek chambers slides

517 coated with L-Polylysin ( $40 \mu \mathrm{g} / \mathrm{ml}$ in pure water) at a density of $0.75 \times 10^{4}$ cells per $\mu 1$ in 20 or 60

$518 \mu 1$ drops. The medium was then replaced by serum-free DMEM-Glutamax-I 1\% P/S, to trigger

519 ependymal differentiation in vitro (DIV0). Cells were either fixed with Paraformaldehyde (4\% in

520 PBS) for 10min or used for live imaging. Fixed cells were examined with an upright

521 epifluorescence microscope (Zeiss Axio Observer.Z1) equipped with Apochromat X63 (NA 1.4)

522 or X100 (NA 1.4) oil-immersion objectives and a Zeiss Apotome with an H/D grid. Images were

523 acquired using Zen software with 230-nm z-steps and analyzed with image-J.

524 For live imaging, differentiating ependymal cells with two bright RFP-tagged centrosomal

525 centrioles were selected and filmed using an inverted spinning disk Nikon Ti PFS microscope

526 equipped with an oil-immersion X100 (NA 1.4) objective, an Evolve EMCCD Camera 
527 (Photometrics), dpss lasers (491 nm, $561 \mathrm{~nm})$, a motorized scanning deck and an incubation 528 chamber $\left(37{ }^{\circ} \mathrm{C} ; 5 \% \mathrm{CO} 2 ; 80 \%\right.$ humidity). Laser intensities and image capture times were 529 respectively set to $20 \%, 50 \mathrm{~ms}$ for $488 \mathrm{~nm}$ and $25 \%, 100 \mathrm{~ms}$ for $561 \mathrm{~nm}$. Images were acquired with

530 Metamorph software at 60 minutes time interval for 24 hours. Image stacks were recorded with a 531 z-distance of $0.7 \mathrm{~mm}$. Four dimensional (x, y, z, t) time-lapse images were analyzed with Image J.

\section{Semi-quantitative RT-PCR}

533 RNA was purified from $1.5 \times 10^{5}$ cells on coverslips using the RNeasy Micro Kit (QIAGEN, 534 74000). Retrotranscription was performed using SuperScript III First-Strand Synthesis System for 535 RT-PCR (Invitrogen, 18080-051). PCR was performed on cDNA using the primers 5'536 AGAAGAACGGCATCAAGGTG-3' and 5'-GAACTCCAGCAGGACCATGT-3' for EGFP 5'537 AACACCGAGATGCTGTACCC-3' and 5'-ACGTAGGTCTCTTTGTCGGC-3' for tagRFP and 5'-ACCCCACCGTGTTCTTCGAC-3' and 5'-CATTTGCCATGGACAAGATG-3' for

539 cyclophilin. Images of the gels were then analysed on ImageJ. The ratio between EGFP or tagRFP 540 and cyclophilin band intensity were calculated. Quantifications of 3 independent experiments were 541 pooled and plotted.

543 Custom written MATLAB script was used to determine the position of the hybrid cilia in 544 multiciliated cells relative to cilia beating direction (can be accessed via the following link:

545 https://drive.google.com/open?id=182KAccJf6YC69WbovKgTwtg62Y5DTadA). First, intensity

546 thresholds for all channels were chosen for and binary images were generated to identify individual 547 basal body and basal foot objects. Individual cells were outlined via manual cell border drawing.

548 Basal body-basal foot pairs were identified based on the pairwise nearest neighbor search with a 549 distance threshold of $\sim 600 \mathrm{~nm}$. The direction of a single cilium was defined as from the weighted 550 center of the basal body object to that of the paired basal foot. All cilia directions in one cell were 
551 determined and the mean direction was regarded as the direction of beating in a cell. The cilia

552 beating angles obtained were transformed into a two-dimensional unit vector: $r_{i}=\left(\begin{array}{l}\cos a_{i} \\ \sin a_{i}\end{array}\right)$. The

553 resultant vector was the average of all the unit vectors in a cell: $\bar{r}=\frac{1}{n} \sum_{i=1}^{n} r_{i}$. The resultant vector

554 length $\mathrm{r}$ was defined as the norm of the resultant vector: $\mathrm{r}=\|\bar{r}\|$. The circular standard deviation

555 was defined as: $c s d=\sqrt{-2 \ln (r)}$. All directions in a single cell were also subject to Rayleigh's

556 test for uniformity distribution. The $p$-value is calculated as: $p$ value $=$

$\left.557 e^{\left(\sqrt{\left(1+4 n+4 n^{2}-4 r_{n}^{2}\right)}-(1+2 n)\right.}\right) ; r_{n}=r \times n$. A p-value $<0.05$ indicated that the cilia in the cell are

558 significantly aligned. Aligned vector length was defined to describe the cilia alignment level in a

559 cell with values ranging from 1 to 0 , with 1 indicating $100 \%$ alignment and 0 indicating no

560 alignment. The mean beating direction of all cilia were defined as the cilia beating direction. The

561 hybrid cilia position relative to the cilia beating direction was measured using the same basal foot

562 and basal body markers in cells whose size is normalized to [-0.5;0.5] both along the cilia beating

563 direction (regarded as cell length) and the direction perpendicular to it (regarded as cell width).

\section{Statistical Analysis}

565 Data was analyzed in Microsoft Excel and Prism software. Statistical tests, sample sizes and 566 number of replicates were specified in figure legends. Differences were regarded as significant if $567 \mathrm{p}<0.05$, unless otherwise stated.

\section{$568 \quad$ Figures}




\section{Figure 1: 3D-SIM and BiolD reveal the molecular architecture and a novel component of basal foot in primary cilia}

a

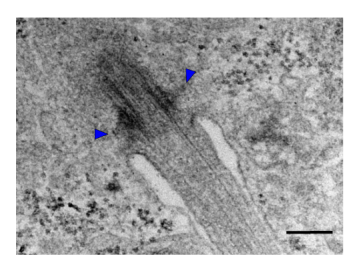

b
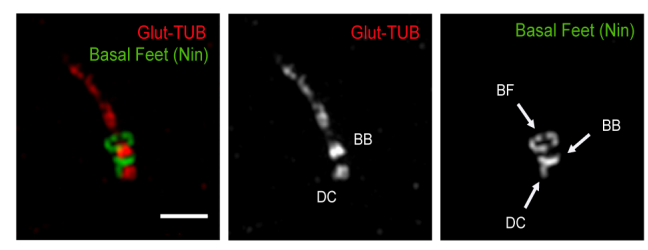

e

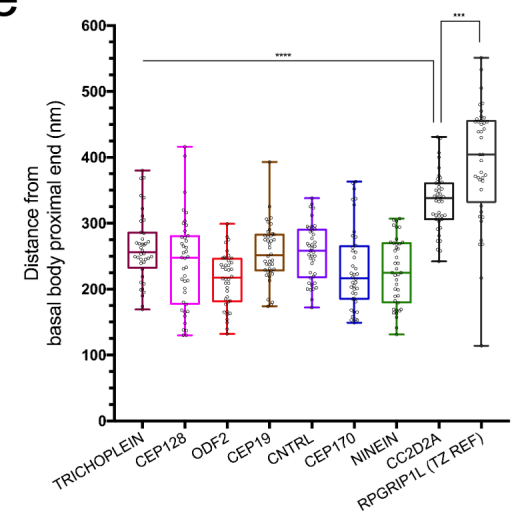

$f$ d

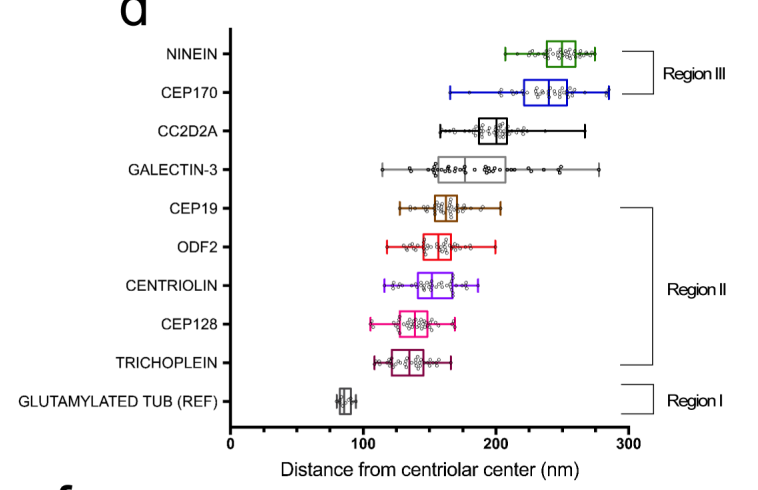

C

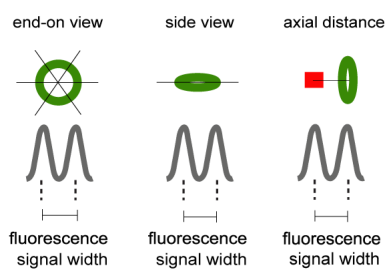

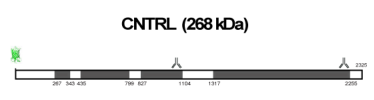

CEP128 (128 kDa)
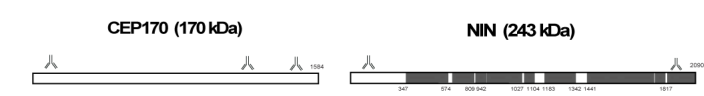

ODF2 (85 kDa)
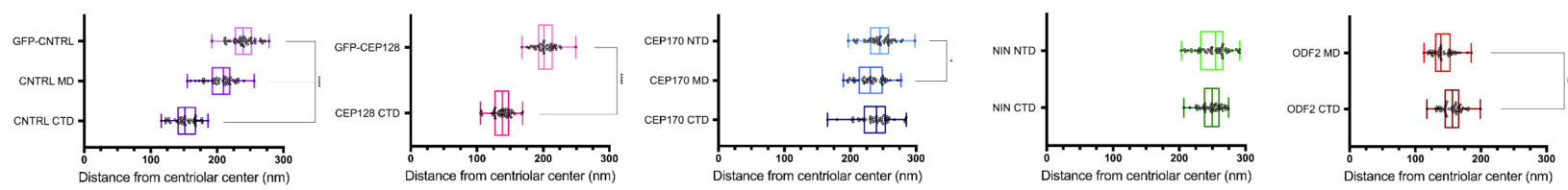

g

Signalling

RIG-I-like receptor pathway

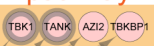
(3.

\section{(36) - Intermediate Filament} CEP128

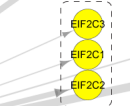

RISC complex Actin

h
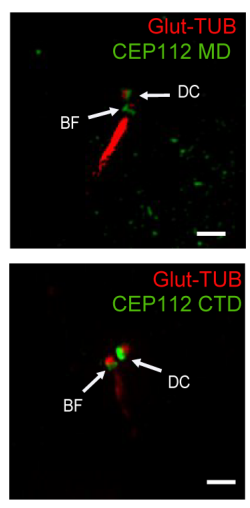

Centriolar Satellite 

basal foot in primary cilia

(a) Representative TEM micrograph of a primary cilium and its basal feet (blue arrowheads) in volume of a primary cilia in RPE-1 cell stained with anti-Ninein (NIN, green) and antiglutamylated tubulin (Glut-TUB, red) antibodies, showing the three known subpopulations of the protein: at the proximal ends of basal body, daughter centriole and at the basal feet (see arrows).

577 Scale bar represents $1 \mu \mathrm{m}$. (c) Cartoon depiction of the strategy used to measure radial and axial 578 distance of basal foot proteins (green) in primary cilia. The radial distance, or distance from the 579 centriolar center, was calculated either from end-on view by dividing each of the ring diameter measurements by two (left) or from side views by measuring the lateral distance of basal foot

581 proteins positioned across the basal body (middle). Axial distance was measured relative to the 582 basal body proximal end (red). (d) Box plot of radial distances of basal foot proteins in primary 583 cilia of RPE-1 cells $(n=40)$. Region assignment of proteins was based on statistical analysis by one-way ANOVA using Tukey's multiple comparison test. Distance measurements of proteins not significantly different from each other were grouped into the same region. (e) Box plot of axial 586 distances of basal foot proteins in primary cilia from RPE-1 cells $(n=40)$. RPGRIP1L was used to 587 label the transition zone. Statistical analysis was done by one-way ANOVA with Tukey's multiple 588 comparison test. (f) Top: linear maps representing protein polypeptide sequences showing the 589 regions recognized by antibodies and the position of GFP insertion. Bottom: Box plot of radial 590 distributions of CNTRL, CEP128, CEP170, NIN and ODF2 in primary cilia of RPE-1 cells using 591 domain specific antibodies. Statistical analyses were conducted using Welch's t-test (for pair-wise 592 comparisons) and Tukey's test (for multiple comparisons). Unless indicated otherwise, the 593 differences are not significant. (g) Diagram showing proteins identified via BioID in close 
594 proximity to CEP128-BirA* in ciliated HEK-293 cells. Arrow thickness is proportional to the

595 number of peptides detected. (h) 2D projection micrographs of 3D-SIM volume of a primary

596 cilium in RPE-1 cell stained with anti-CEP112 (green) antibodies labelling middle domain (MD,

597 left) and C-terminal domain (CTD, right), and anti-Glut-TUB (red) antibody, showing two distinct

598 subpopulations of the protein: at the proximal ends of daughter centriole and at the basal feet (see

599 arrows). Scale bars represent $1 \mu \mathrm{m}$.

600

601

602

603

604

605

606

607

608

609

610

611

612

613

614

615

616

617 


\section{Figure 2: The conserved and distinct architectural features of basal foot in motile cilia}

a
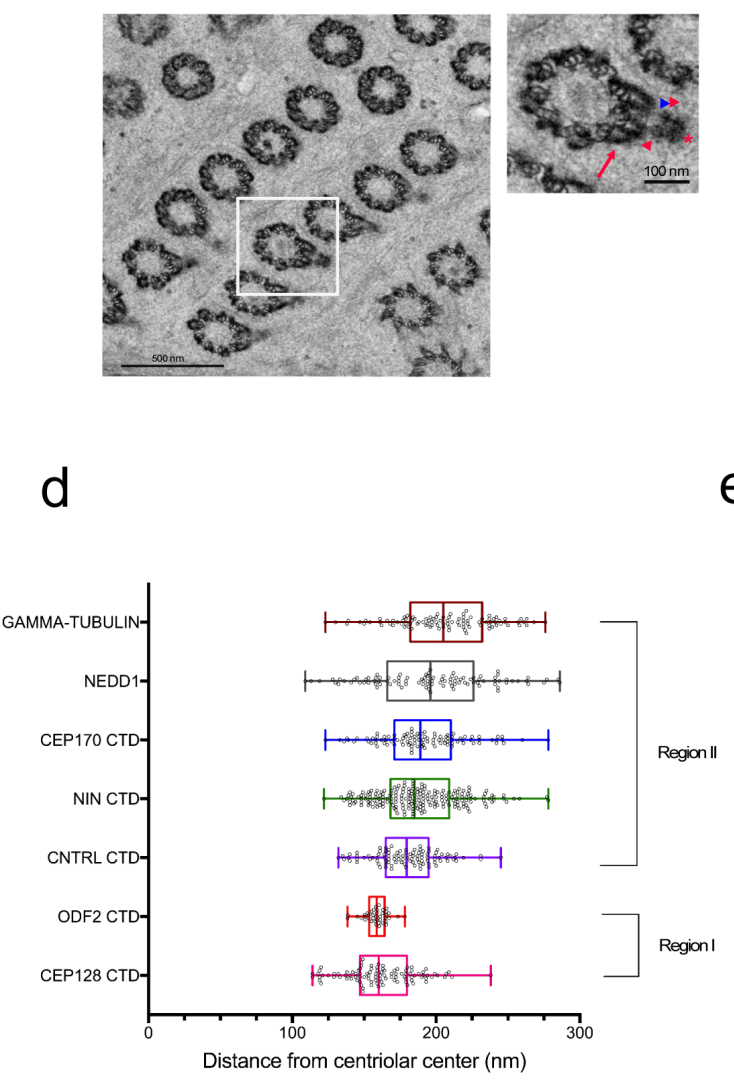

f

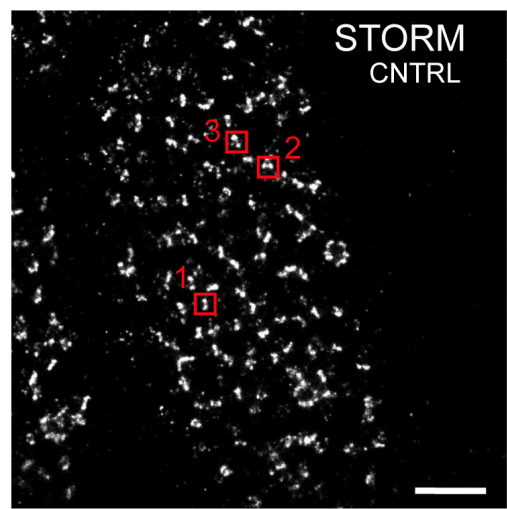

b

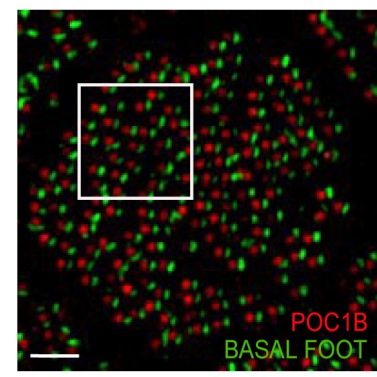

e
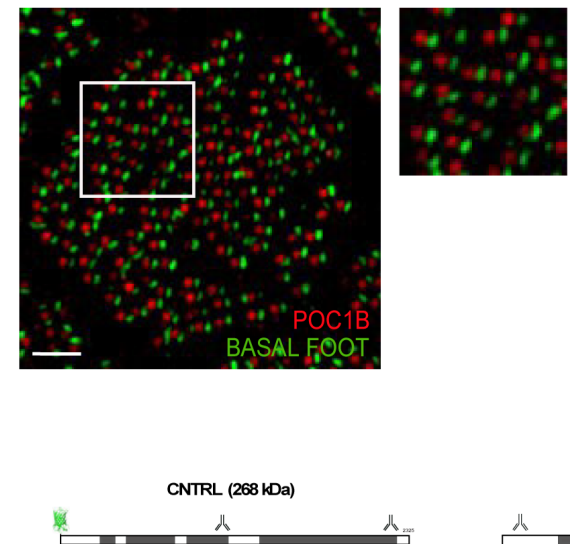

C

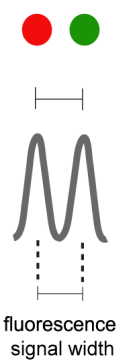

NIN (243 ka)

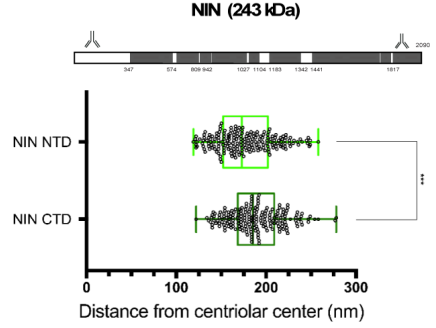

CEP170 (170 kDa)
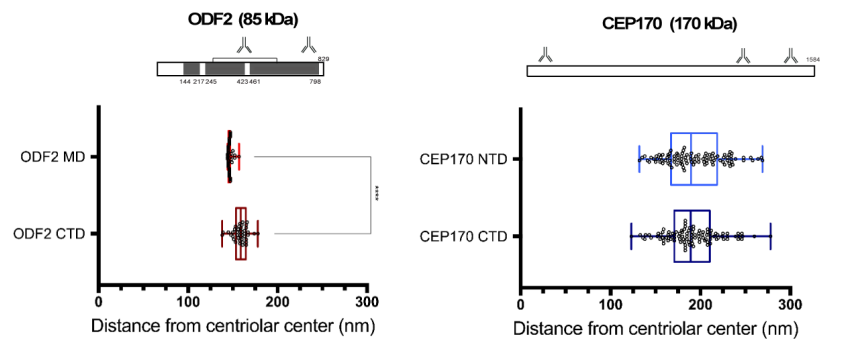

g
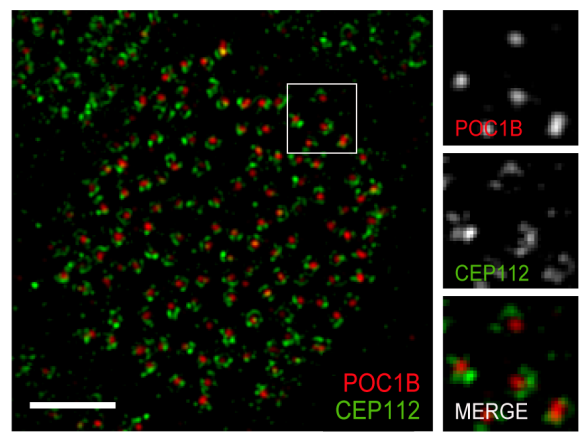
Figure 2. The conserved and distinct architectural features of basal foot in motile cilia

623 (a) Left: Representative TEM micrograph from a cross section of a human airway multiciliated 624 cell. Scale bar represents $200 \mathrm{~nm}$. Right: High-magnification view of the boxed area. Note three 625 main electron-dense regions of the basal foot. Red asterisk denotes basal cap region, red 626 arrowheads the spherical symmetrical structures, blue arrowhead the fibril region and red arrow 627 the arch-region. Scale bar represents $100 \mathrm{~nm}$. (b) Left: 2D projection micrograph of 3D-SIM 628 volume of an airway epithelial multiciliated cell (end-on view) labeled with an antibody 629 recognizing a basal body protein (POC1B, red) and a basal foot protein (CNTRL, green). Scale 630 bar represents $1 \mu \mathrm{m}$. Right: High-magnification view of boxed area. (c) Cartoon depiction of the 631 strategy used to measure radial distance of basal foot proteins (green) in motile cilia of human 632 airway multiciliated cells using end-on view. Radial distance was measured relative to the basal 633 body center (red). (d) Box plot of radial distributions of basal foot proteins in human airway 634 multiciliated cells ( $\mathrm{n}=80)$. Region assignment was done based on one-way ANOVA with Tukey's 635 multiple comparison test. Proteins whose distances were not significantly different were grouped 636 into the same region. (e) Top: linear maps representing protein polypeptide sequences showing the 637 regions recognized by antibodies. Bottom: Box plot of radial distributions of CNTRL, NIN, ODF2 638 and CEP170 in motile cilia of human airway multiciliated cells using domain specific antibodies. $639(\mathrm{n}=80)$. Statistical analyses were conducted using Welch's t-test for pair-wise comparisons. (f) 640 Left: 2D-STORM micrograph of human airway multiciliated cells labeled with anti-CNTRL 641 antibody. Scale bar represents $1 \mu \mathrm{m}$. Right: High-magnification views of boxed areas. (g) 2D 642 projection micrograph of 3D-SIM volume of an airway epithelial multiciliated cell (end-on view) 643 labeled with an antibody recognizing a basal body protein (POC1B, red) and CEP112 CTD 644 antibody. Scale bar represents $2 \mu \mathrm{m}$. 


\section{Figure 3. Super resolution mapping of basal foot reveals a novel type of cilia in airways multiciliated cells}

a
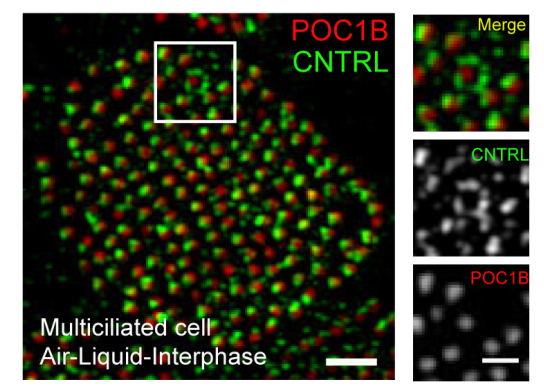

d
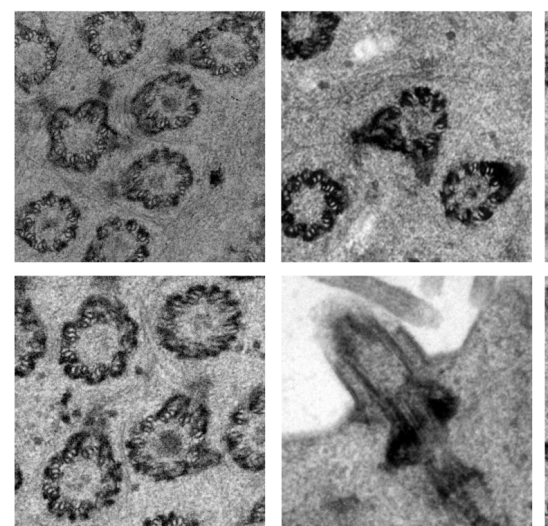

b

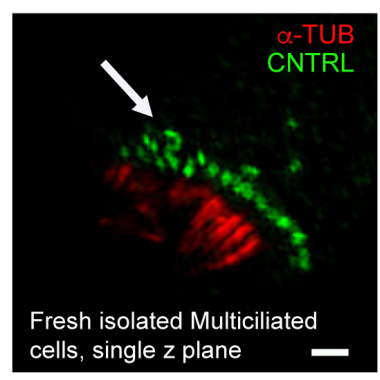

C

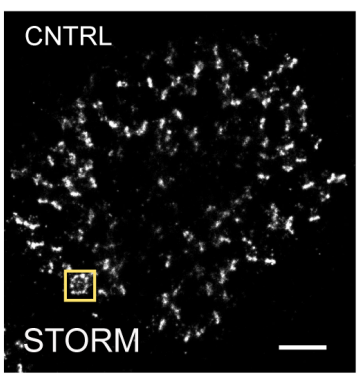

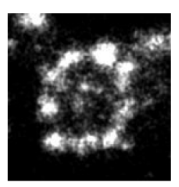

e
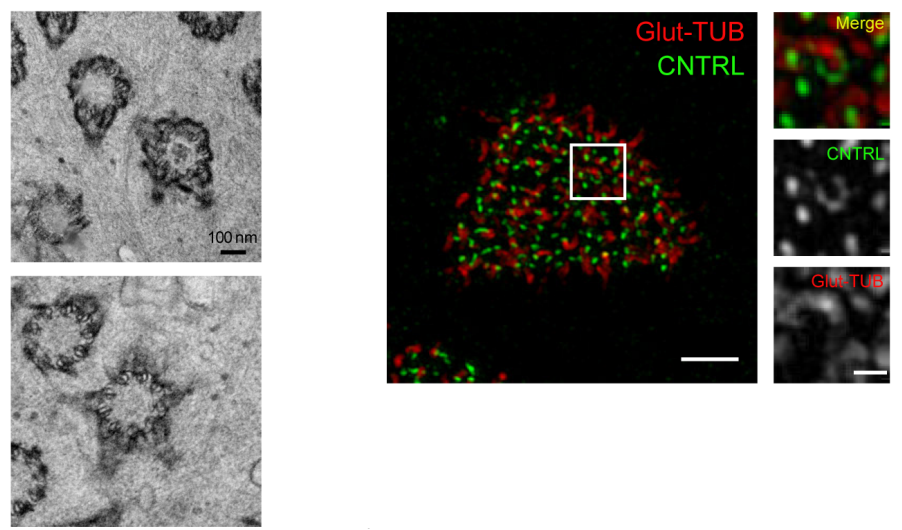

multiciliated cells

(a) Left: 2D projection micrograph of 3D-SIM volume of an airway multiciliated cell grown on Air-Liquid-Interface (ALI), labeled with anti-CNTRL (green) and anti-POC1B (red) antibodies. Note the ring-like pattern of CNTRL localization encircling the basal body labeled by POC1B. Right: High-magnification view of boxed area. Scale bars represent $1 \mu \mathrm{m}$ (left) and $500 \mathrm{~nm}$ (right). (b) $2 \mathrm{D}$ projection micrograph of 3D-SIM volume of human airway multiciliated cells freshly isolated from healthy individual, labeled with anti-CNTRL (green) and anti-alpha-tubulin (red) antibodies, showing the presence of the basal body with multiple basal feet. Scale bar represents 1 $\mu \mathrm{m}$. (c) Left: 2D-STORM micrograph of airway multiciliated cell labeled with anti-CNTRL antibody, showing a distinct ring-like distribution of CNTRL. Right: High-magnification view of

667 boxed area. Scale bars represent $1 \mu \mathrm{m}$. (d) Collage of representative TEM micrographs showing 668 basal bodies harboring multiple basal feet in human airway multiciliated cell. Scale bars represent $669100 \mathrm{~nm}$. (e) Left: 2D projection micrographs of 3DSIM volume of an airway multiciliated cell labeled with anti-CNTRL (green) and anti-Glut-TUB (red) antibodies. Note the axoneme

671 emanating from ring-like structure labeled with CNTRL. Right: High-magnification view of boxed 672 area with individual channels. Scale bars represent $2 \mu \mathrm{m}$ (left) and $500 \mathrm{~nm}$ (right). 


\section{Figure 4. The novel cilium has hybrid features between primary and motile cilia}

a

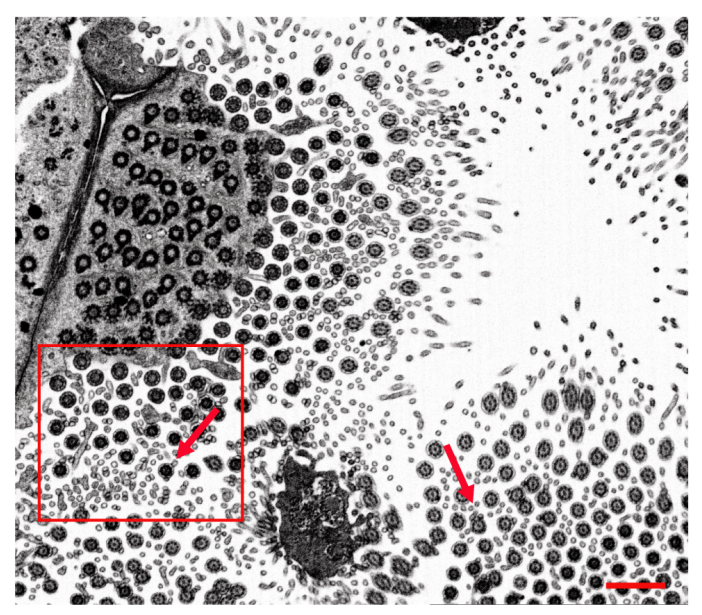

b
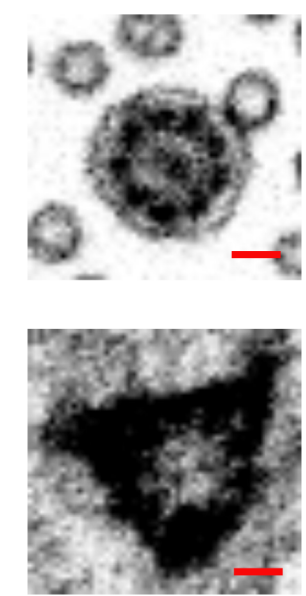

d

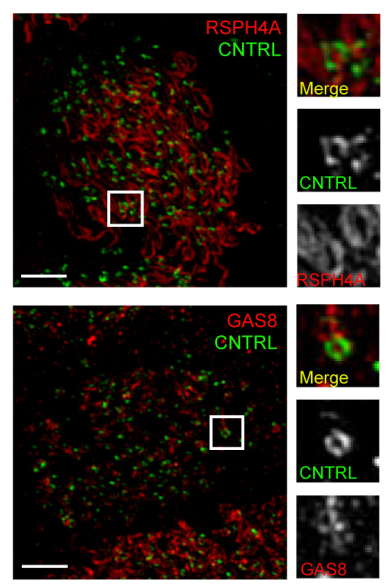

C

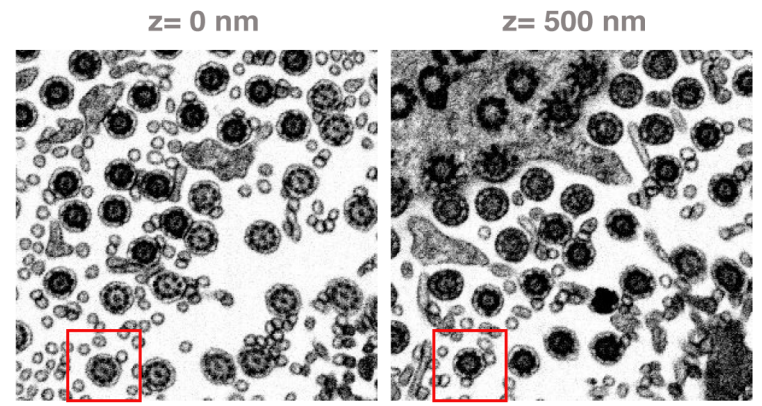

$z=1040 \mathrm{~nm}$

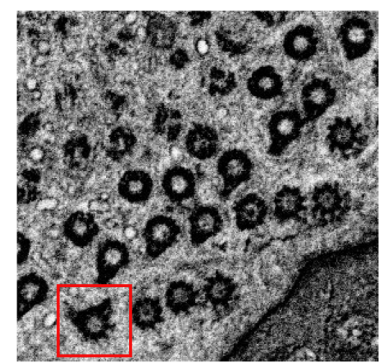

$z=1120 \mathrm{~nm}$

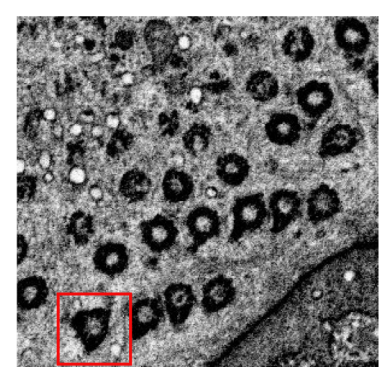

$\mathrm{z}=1060 \mathrm{~nm}$

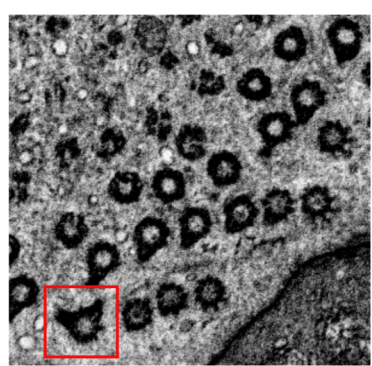

$\mathrm{z}=1140 \mathrm{~nm}$

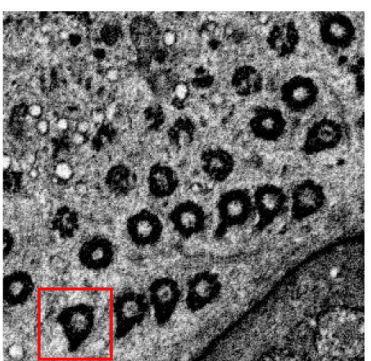

$z=1000 \mathrm{~nm}$

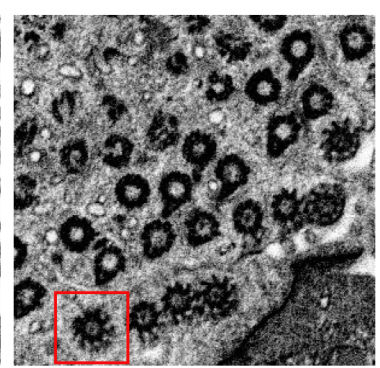

$\mathrm{z}=1080 \mathrm{~nm}$

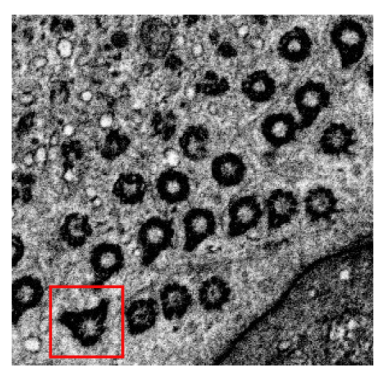

$\mathrm{z}=1160 \mathrm{~nm}$

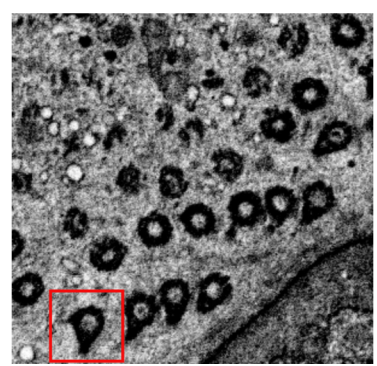

$z=1020 \mathrm{~nm}$

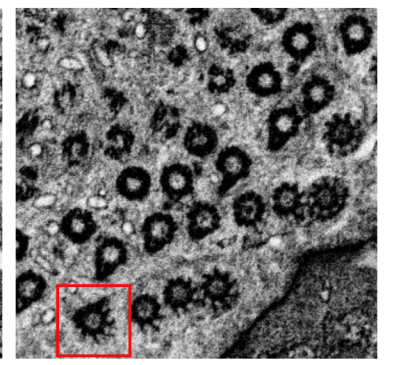

$\mathrm{z}=1100 \mathrm{~nm}$

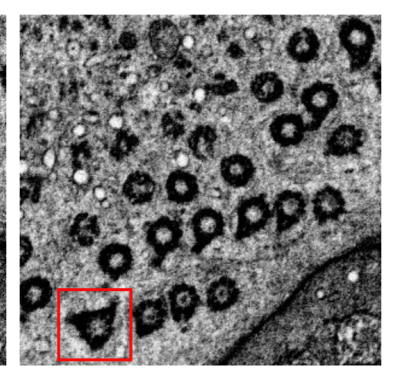

$\mathrm{z}=1660 \mathrm{~nm}$

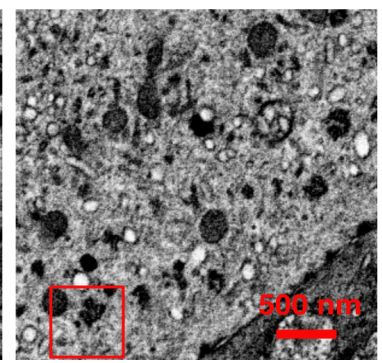




\section{Figure 4. The novel cilium has hybrid features between primary and motile cilia}

682 (a) Representative section from FIB-SEM tomogram of human multiciliated cells. Arrows indicate

683 basal bodies with multiple basal feet. Scale bar represents $1 \mu \mathrm{m}$. (b) High-magnification view of

684 boxed area in (a) at different $\mathrm{z}$ position of the tomogram from $\mathrm{z}=0 \mathrm{~nm}$ to $\mathrm{z}=1660 \mathrm{~nm}$. Note the

685 hybrid cilium axoneme and central pair $(\mathrm{z}=0 \mathrm{~nm})$, transition fibers $(\mathrm{z}=1000-1040 \mathrm{~nm})$, multiple

686 basal feet $(\mathrm{z}=1160-1160 \mathrm{~nm})$ and the absence of the endocytic pocket $(\mathrm{z}=1660 \mathrm{~nm})$. Scale bar

687 represents $500 \mathrm{~nm}$. (c) A high-magnification view of boxed area in (b) highlighting the basal body

688 with a central pair and multiple basal feet. Scale bar represents $100 \mathrm{~nm}$. (d) 2D projection

689 micrographs of 3D-SIM volume of human airway multiciliated cells (left), and high-magnification

690 views of boxed areas (right), labeled with anti-CNTRL (green), anti-RSPH4A (red, top) and anti-

691 GAS8 (red, bottom) antibodies. Scale bars represent $2 \mu \mathrm{m}$.

692

693

694

695

696

697

698

699

700

701

702

703

704 


\section{Figure 5: Hybrid cilium is a conserved feature of multiciliated cells and originates from parental centrioles}

a

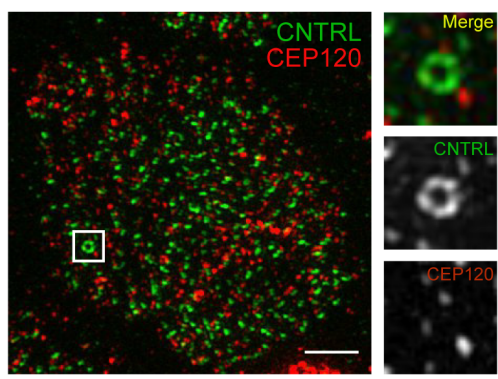

Mouse Tracheal Multiciliated Cells

C

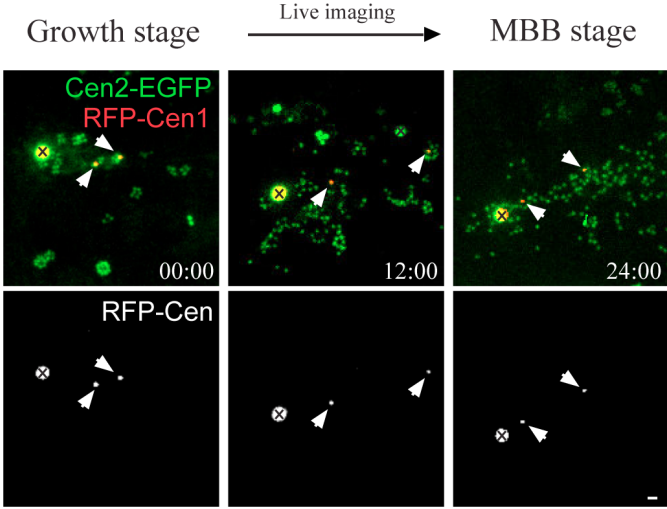

e

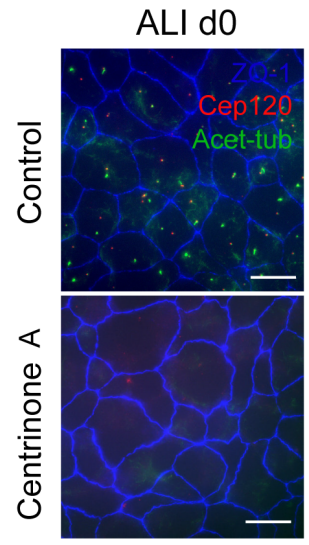

g

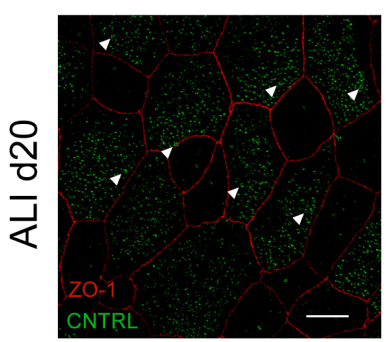

Control
ALI d20
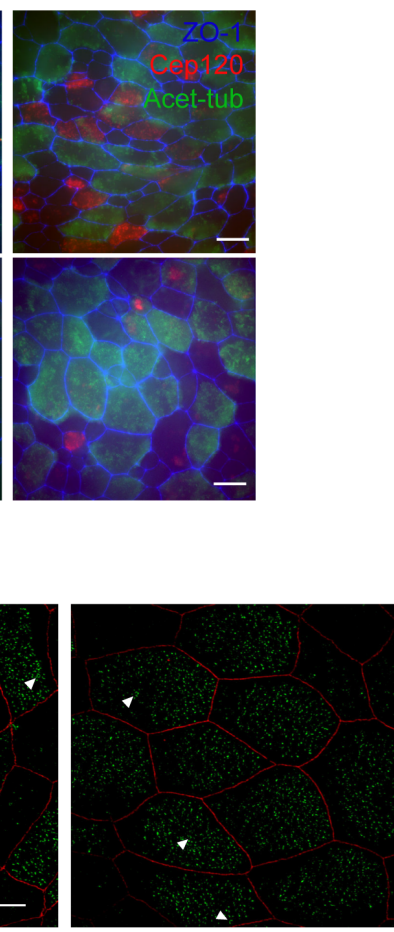

Centrinone A b

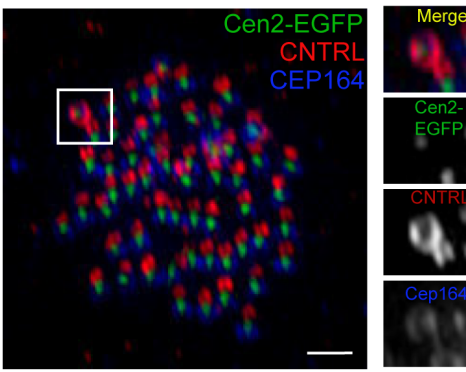

Mouse Ependymal Multiciliated Cells

d
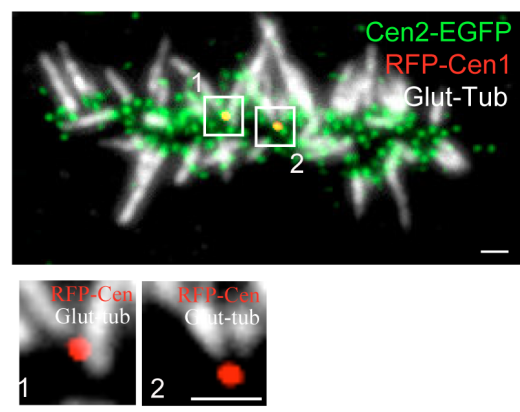
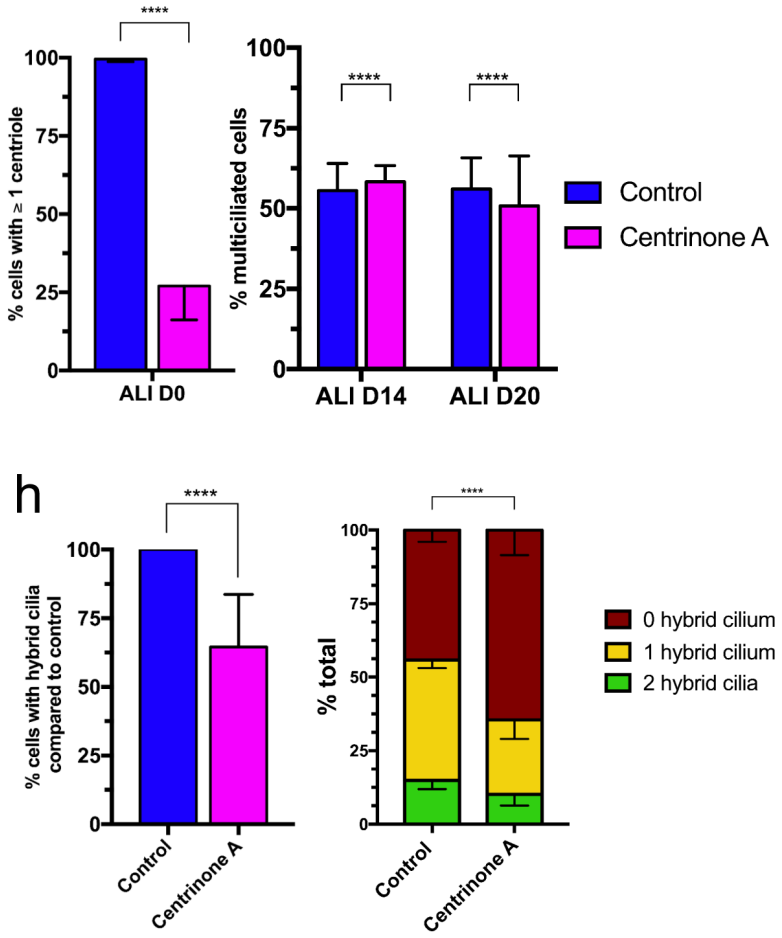

$\square 0$ hybrid cilium

$\square 1$ hybrid cilium $\square 2$ hybrid cilia 
(a) Left: 2D projection micrograph of 3D-SIM volume of mouse tracheal multiciliated cell (ALI D20), labeled with anti-CNTRL (green) and anti-CEP120 (red) antibodies. Right: Highmagnification view of boxed area with individual channels. Scale bar represents $2 \mu \mathrm{m}$. (b) Left: 2D projection micrograph of 3D-SIM volume of adult mouse ependymal multiciliated cells (P16), labeled with GFP-Centrin2, anti-CNTRL (red) and anti-CEP164 (blue) antibodies. Right: High-

714 TagRFP-Cen1 centrosomal centrioles during centriole amplification in primary cultured 715 ependymal progenitors from Cen2-EFGP mice. Newly formed EGFP+ procentrioles are growing 716 from deuterosomes and RFP+ centrosomal centrioles (00:00) before disengaging from their 717 growing platforms (12:00) and gathering all together in the basal body patch (24:00). Arrowheads 718 point to RFP+ centrosomal centrioles. A «x» sign marks centrin aggregates. (d) 2D projection 719 micrograph from immunostaining experiment of primary cultured ependymal multiciliated cells 720 labeled with antibody labeling glutamylated-tubulin (GT335) and RFP+ centrosomal centrioles

721 that are retained in the basal body patch. Note cilia growing from centrosomal centrioles (e) 2D 722 projection fluorescence micrograph of volumes of mouse tracheal multiciliated cells at ALI D0 723 (left) and ALI D20 (right), treated with DMSO control (top) or Centrinone A (bottom) and labeled 724 with anti-acetylated tubulin (green), anti-CEP120 (red) and anti-ZO-1 (blue) antibodies. Scale bars 725 represent $10 \mu \mathrm{m}$. (f) Bar graph showing percentage of cells with more than one centrioles at ALI 726 D0 (left) and percentage of multiciliated cells at ALI D14 and D20 (right) in DMSO control (blue) 727 or Centrinone A (pink); $\mathrm{n}>6000$. Statistical analysis was done using Cochran-Mantel-Haenszel 728 test. (g) 2D projection micrograph of 3D-SIM volume of mouse tracheal multiciliated cells at ALI 729 D20 treated with DMSO control (left) or Centrinone A (right), labeled with anti-CNTRL (green) 
730 antibody. Arrowheads indicate CNTRL rings. Scale bar represents $5 \mu \mathrm{m}$. (h) Left: Bar graph

731 representing percentage of cells with hybrid cilium in DMSO control (blue) and Centrinone A-

732 treated (pink) cells, normalized to control condition; $\mathrm{n}>800$. Statistical analysis was done using

733 Cochran-Mantel-Haenszel test. Right: Bar graph representing percentage of cells with none (red),

734 one (yellow) or two (green) hybrid cilia in ALI D20 mouse tracheal multiciliated cells treated with

735 DMSO control (left) or Centrinone A (right); $\mathrm{n}>800$.

736

737

738

739

740

741

742

743

744

745

746

747

748

749

750

751

752

753 


\section{Figure 6. Hybrid Cilium is a signalling centre whose position is dependent on flow}

a

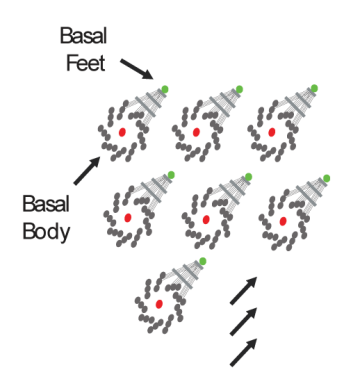

cilia beating direction

b

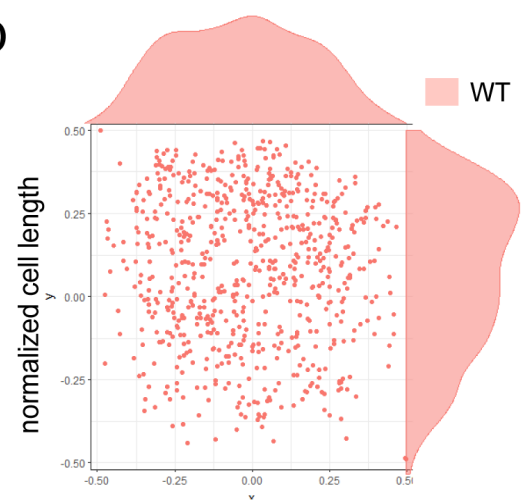

normalized cell width

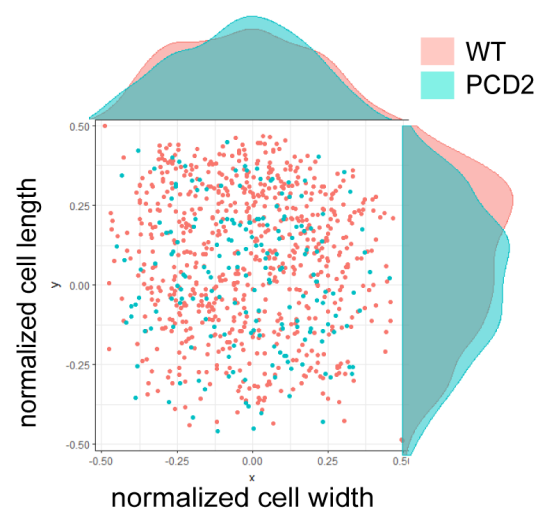

d
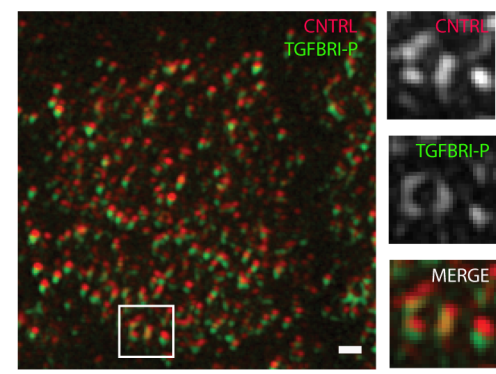

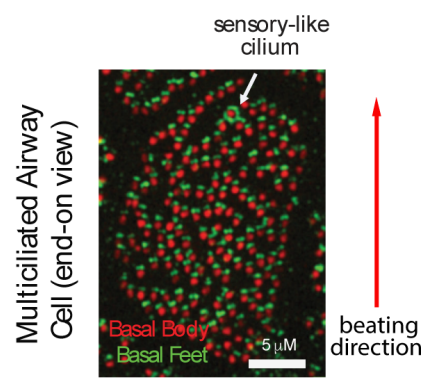

3DSIM image

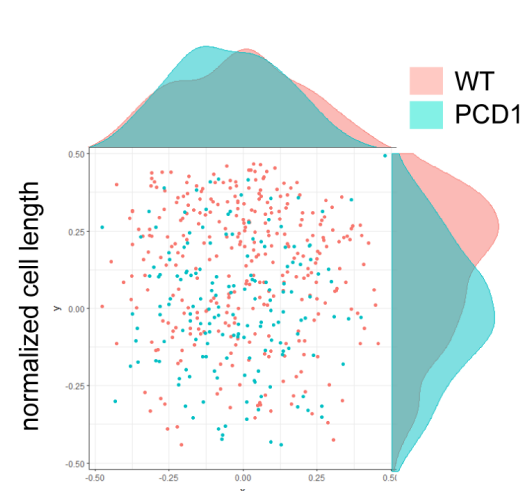

normalized cell width

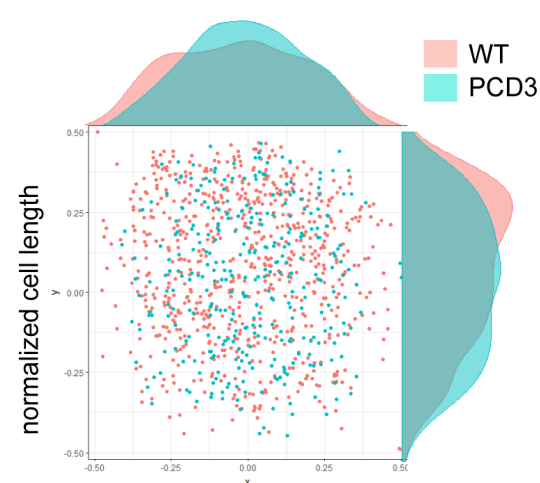

normalized cell width

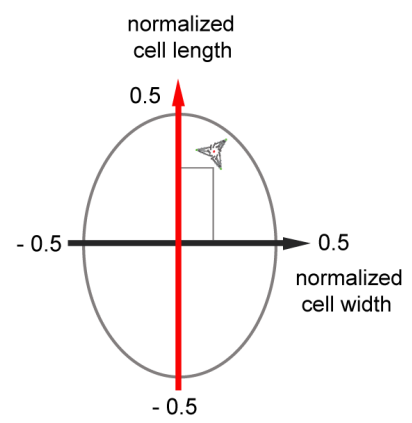

C
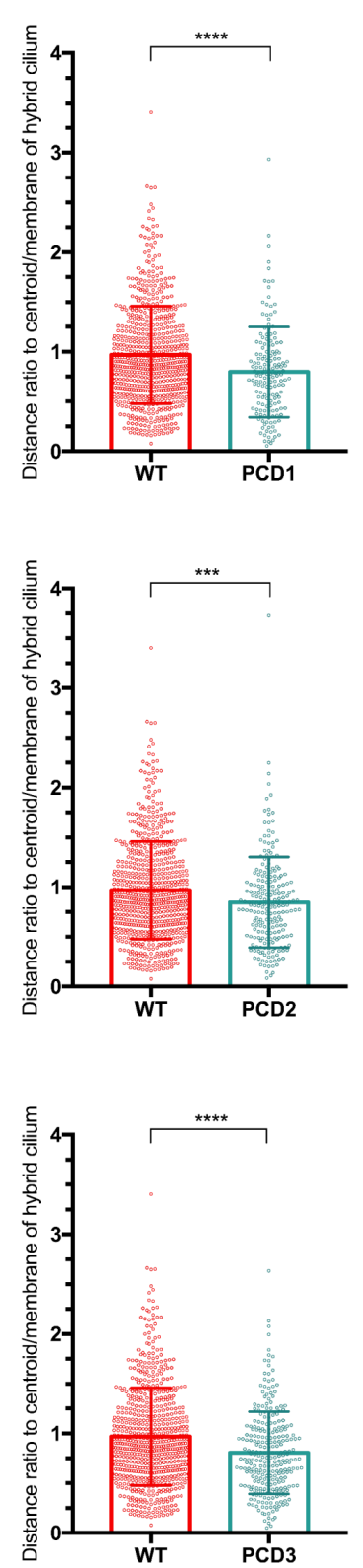
(a) Left: Cartoon depiction of the strategy for analysis of the position of the hybrid cilium. The rotational polarity of basal bodies-basal feet pairs, cell width is assigned as perpendicular to the direction of ciliary beating. Right: MATLAB-based analysis to assess rotational polarity in multiciliated cells. (b) Scatterplot showing the cumulative distribution of hybrid cilia along normalized cell width and cell length in human airway multiciliated cells from healthy individuals, indicating a positional bias toward the direction of ciliary beating. Each dot represents a hybrid cilium in a cell; $n=694$. (c) Scatterplot-bar graphs showing distribution of ratio of hybrid ciliumcell centroid distance to hybrid cilium-cell membrane shortest distance of human airway multiciliated cells from healthy individuals (red, $n=687$ ) or PCD patients (PCD1-3) with immotile

767 cilia caused by loss-of-function mutations in DNAH5 and DNAH11 (blue, n>180). Each dot represents the position of a hybrid cilium in a cell. Statistical analysis was done using Welch's ttest. (d) Left: 2D projection micrograph of 3D-SIM volume of human ALI multiciliated cell treated with TGF $\beta 1$ ligand $(20 \mathrm{ng} / \mathrm{ml} ; 30 \mathrm{~min})$, labeled with anti-phospho-TGFBRI (green) and antiCNTRL (red) antibodies. Right: High-magnification view of boxed area with individual channels.

772 Scale bar represents $500 \mathrm{~nm}$.

\section{Acknowledgements}

775 This project is funded by CIHR program grant \# 391917 to VM and SD; National Heart, Lung and 776 Blood Institute (R01-HL128370) and National Institutes of Diabetes and Digestive and Kidney 777 Diseases (R01-DK108005) to MRM; Z.L. was supported by the SickKids Restracomp Fellowship;

778 The authors acknowledge PCD patients and volunteers for providing nasal cells for this study, 
779 Julie Avolio for help with nasal cell scraping. Jia Zhou, Cindy Fang, Alexandra Albulescu and

780 Jasmine Kang assisted in data analysis. Douglas Holmyard (EM facility, The Hospital for Sick

781 Children) prepared TEM and FIB-SEM samples and helped set up EM imaging. McGill EM

782 facility for FIB-SEM acquisition. We thank Profs Bornens, Pelletier, Cheeseman, Kyung Lee,

783 Elsasser, Avidor-Reiss for generously sharing antibodies and plasmids.

\section{$\underline{\text { Author Contributions }}$}

786 Q.P.H.N. designed and conducted experiments, collected and analyzed the data, wrote the 787 manuscript. Z.L. wrote MATLAB scripts and did STORM experiments. L.Z., H.O., W.F. and T.M. 788 helped with airway multiciliated cells culturing system; RN performed the mouse tracheal epithelia 789 cell experiments; MM and VM conceived and designed the MTEC-centrinone experiments; N.D., 790 M.A and A.M. conceived and performed the ependymal cells pulse chase experiments; E.C., E.L.

791 and B.R. performed BioID experiments; S.D. provided PCD patients cells, K.C. helped with 792 sample preparation for FIB-SEM data collection and acquired data; V.M. conceived the project, 793 designed experiments, collected data, analyzed data and wrote the manuscript.

\section{Competing Financial Interests}

796 The authors declare no competing financial interests.

\section{$797 \underline{\text { References }}$}

1. Reiter, J. \& Leroux, M. Genes and molecular pathways underpinning ciliopathies. Nat. Rev. Mol. Cell Biol. 18, 533 (2017). 
2. Fliegauf, M., Benzing, T. \& Omran, H. When cilia go bad: cilia defects and ciliopathies. Nat. Rev. Mol. Cell Biol. 8, 880 (2007).

3. Clare, D. K. et al. Basal foot MTOC organizes pillar MTs required for coordination of beating cilia. Nat Commun. 5 (2014).

4.. Kunimoto, K. et al. Coordinated Ciliary Beating Requires Odf2-Mediated Polarization of Basal Bodies via Basal Feet. Cell 148, 189-200 (2012).

5. Tateishi, K. et al. Two appendages homologous between basal bodies and centrioles are formed using distinct Odf2 domains. J. Cell Biol. 203, 417 (2013).

6. Spassky, N. \& Meunier, A. The development and functions of multiciliated epithelia. Nat. Rev. Mol. Cell Biol. 18, 423 (2017).

7. Jain, R. et al. Temporal Relationship between Primary and Motile Ciliogenesis in Airway Epithelial Cells. Am. J. Respir. Cell Mol. Biol. 43, 731-739 (2010).

8. Boisvieux-Ulrich, E., Sandoz, D. \& Allart, J. P. Determination of ciliary polarity precedes differentiation in the epithelial cells of quail oviduct. Biol. Cell 72, 3-14 (1991).

9. Frisch, D. \& Farbman, A. I. Development of order during ciliogenesis. Anat. Rec. 162, 221-231 (1968).

10. Vladar, E., Antic, D. \& Axelrod, J. Planar Cell Polarity Signaling: The Developing Cell's Compass. CSH PERSPECT BIOL 1, a002964 (2009).

11. Vladar, E., Bayly, R. D.,Sangoram, A. M., Scott, M. P. \& Axelrod, J. D. Microtubules Enable the Planar Cell Polarity of Airway Cilia. Curr. Biol. 22, 2203-2212 (2012).

12. Herawati, E et al. Multiciliated cell basal bodies align in stereotypical patterns coordinated by the apical cytoskeleton. J Cell Biol. 214, 571-586 (2016). 
13. Luo, $\mathrm{W}$ et al. Cilia distribution and polarity in the epithelial lining of the mouse middle ear cavity Sci. Rep. 7 (2017).

14. Zariwala, M. A., Knowles, M. R. \& Omran, H. Genetic defects in ciliary structure and function. Annu. Rev. Physiol. 69, 423-450 (2007).

15. Shapiro, A. J et al. Diagnosis, monitoring, and treatment of primary ciliary dyskinesia: PCD foundation consensus recommendations based on state of the art review Pediatr Pulmonol. 51, 115-132 (2015).

16. Knowles, M. R, Daniels, L. A., Davis, S. D, Zariwala, M. A. \& Leigh, M. W. Primary Ciliary Dyskinesia. Recent Advances in Diagnostics, Genetics, and Characterization of Clinical Disease. Am J Respir Crit Care Med. 188, 913-922 (2013).

17. Mazo, G., Soplop, N., Wang, W-J., Uryu K. \& Tsou, M-F. B. Spatial Control of Primary Ciliogenesis by Subdistal Appendages Alters Sensation-Associated Properties of Cilia Dev. Cell 39, 424-437 (2016).

18. Galati, D. F., Mitchell, B. J. \& Pearson, C. G. Subdistal appendages stabilize the ups and downs of ciliary life. Dev. Cell 39, 387-389 (2016).

19. Graser, S. et al. Cep164, a novel centriole appendage protein required for primary cilium formation. J Cell Biol. 79, 321-330 (2007).

20. Hoey, D. A., Downs, M. E. \& Jacobs, C. R. The mechanics of the primary cilium: an intricate structure with complex function. J Biomech 45, 17-26 (2012).

21. Sorokin, S. P. Reconstructions of centriole formation and ciliogenesis in mammalian lungs. J. Cell Sci. 3, 207-230 (1968).

22. Winey, M. \& O'Toole, E. Centriole structure. Phil. Trans. R. Soc. B. 369, 20130457 (2014). 
23. Uzbekov, R. \&Alieva, I. Who are you, subdistal appendages of centriole? Open Biol. 8, $180062(2018)$.

24. Paintrand, M., Moudjou, M., Delacroix, H. \& Bornens, M. Centrosome organization and centriole architecture: their sensitivity to divalent cations. J. Struct. Biol. 8, 107-128 (1992).

25. Albrecht-Buehler, G. \& Bushnell, A. The ultrastructure of primary cilia in quiescent 3 T3 cells. Exp. Cell Res. 126, 427-37 (1980).

26. Mogensen, M. M., Malik, A., Piel, M., Bouckson-Castaing, V. \& Bornens, M. Microtubule minus-end anchorage at centrosomal and non-centrosomal sites: the role of ninein. J. Cell Sci. 113, 3013-3023 (2000).

27. Nakagawa, Y., Yamane, T., Okanoue, T., Tsukita, S. \& Tsukita, S. Outer dense fiber 2 is a widespread centrosome scaffold component preferentially associated with mother centrioles: its identification from isolated centrosomes. Mol. Biol. Cell 12, 1687-1697 (2001).

28. Ishikawa, H., Kubo, A., Tsukita, S. \& Tsukita, S. Odf2-deficient mother centrioles lack distal/subdistal appendages and the ability to generate primary cilia. Nat. Cell Biol. 7, 517$524(2005)$.

29. Veleri, S. et al. Ciliopathy-associated gene $\mathrm{Cc} 2 \mathrm{~d} 2 \mathrm{a}$ promotes assembly of subdistal appendages on the mother centriole during cilia biogenesis. Nat. Commun. 5 (2014).

30. Guarguaglini, G. et al. The forkhead-associated domain protein Cep170 interacts with Polo-like kinase 1 and serves as a marker for mature centrioles. Mol. Biol. Cell 6, 10951107 (2005). 
31. Chang, P., Giddings, T. H., Winey, M. \& Stearns, T. $\varepsilon$-Tubulin is required for centriole duplication and microtubule organization. Nat. Cell Biol. 5, 71-76 (2003).

32. Gromley, A. et al. A novel human protein of the maternal centriole is required for the final stages of cytokinesis and entry into S phase. J. Cell Biol. 161, 535-545 (2003).

33. Ibi, M. et al. Trichoplein controls microtubule anchoring at the centrosome by binding to Odf2 and ninein. J. Cell Sci. 124, 857-864 (2011).

34. Gupta, G. D. et al. A dynamic protein interaction landscape of the human centrosomecilium interface. Cell 163, 1484-1499 (2015).

35. Huang, N. et al. Hierarchical assembly of centriole subdistal appendages via centrosome binding proteins CCDC120 and CCDC68. Nat. Commun. 8, 15057 (2017).

36. Tateishi, K., Nishida, T., Inoue, K. \& Tsukita, S. Three-dimensional Organization of Layered Apical Cytoskeletal Networks Associated with Mouse Airway Tissue Development. Sci. Rep. 7, 43783 (2017).

37. Hehnly, H., Chen, C-T., Powers, C. M., Liu, H-L. \& Doxsey, S. The centrosome regulates the Rab11-dependent recycling endosome pathway at appendages of the mother centriole. Curr. Biol. 22, 1944-1950 (2012).

38. Delgehyr, N., Sillibourne, J. \& Bornens, M. Microtubule nucleation and anchoring at the centrosome are independent processes linked by ninein function. J Cell Sci. 118, 1565 $1575(2005)$.

39. Welburn J. P. I. \& Cheeseman, I. M. The microtubule-binding protein Cep 170 promotes the targeting of the kinesin-13 depolymerase Kif2b to the mitotic spindle. Mol. Biol. Cel, 23, 4786-4795 (2012). 
40. Lamla, S. \& Nigg, E. A. Functional Characterisation of the Centrosomal Protein Cep170. Doctoral Thesis (2009).

41. Gustafsson, M. G. L. Surpassing the lateral resolution limit by a factor of two using structured illumination microscopy. J. Microsc. 198, 82-87 (2000).

42. Sydor, A. M., Czymmek, K. J., Puchner, E. M. \& Mennella, V. Super-Resolution Microscopy: From Single Molecules to Supramolecular Assemblies. Trends Cell Biol. 25, $730-48$ (2015).

43. Schermelleh, L. et al. Subdiffraction Multicolor Imaging of the Nuclear Periphery with 3D Structured Illumination Microscopy. Science 320, 1332-1336 (2008).

44. Ou, Y. Y., Mack, G. J., Zhang, M. \& Rattner, J. B. CEP110 and ninein are located in a specific domain of the centrosome associated with centrosome maturation. J. Cell Sci. 115, 825-1835 (2002).

45. Anderson, R. G. The three-dimensional structure of the basal body from the rhesus monkey oviduct. J. Cell Biol. 54, 246-265 (1972).

46. Shi, X. et al. Super-resolution microscopy reveals that disruption of ciliary transition-zone architecture causes Joubert syndrome. Nat. Cell Biol. 19, 1178 (2017).

47. Mennella, V. et al. Subdiffraction-resolution fluorescence microscopy reveals a domain of the centrosome critical for pericentriolar material organization. Nat. Cell Biol. 14, 1159, (2012).

48. Mennella, V., Agard, A. D., Huang, B. \& Pelletier, L. Amorphous no more: subdiffraction view of the pericentriolar material architecture. Trends Cell Biol. 24, 188-194 (2014). 
49. Lawo, S., Hasegan, M., Gupta, G. D., Pelletier, L. Subdiffraction Imaging of Centrosomes Reveals Higher-Order Organizational Features of Pericentriolar Material. Nat. Cell Biol. 14, 1148-1158 (2012).

50. Jakobsen, L. et al. Novel asymmetrically localizing components of human centrosomes identified by complementary proteomics methods. EMBO J. 30, 1520-1535 (2011).

51. Venoux, M. et al. Poc1A and Poc1B act together in human cells to ensure centriole integrity. J. Cell Sci. 126, 163-175 (2013).

52. Sydor, A. M. et al. PPP1R35 is a novel centrosomal protein that regulates centriole length in concert with the microcephaly protein RTTN. Elife 7, e37846 (2016).

53. Kollman, J. M., Merdes, A., Mourey, L. \& Agard, D. A. Microtubule nucleation by $\gamma-$ tubulin complexes. Nat. Rev. Mol. Cell Biol. 12, 709-21 (2011).

54. Lüders, J., Patel, U. K., \& Stearns, T. GCP-WD is a gamma-tubulin targeting factor required for centrosomal and chromatin-mediated microtubule nucleation. Nat. Cell Biol. 8, 137-47 (2006).

55. McAuley, J. R. \& Anand, V. K. Clinical significance of compound cilia. Otolaryngol Head Neck Surg. 118, 685-7 (1998).

56. Olbrich, H. et al. Loss-of-function GAS8 mutations cause primary ciliary dyskinesia and disrupt the nexin-dynein regulatory complex. Am J Hum Genet 94, 546-554 (2015).

57. Frommer, A. et al. Immunofluorescence Analysis and Diagnosis of Primary Ciliary Dyskinesia with Radial Spoke Defects. A.m J. Respir. Cell Mol. Biol. 53, 563-73 (2015).

58. Al Jord, A., Lemaitre, A-I., Delgehyr, N., Faucourt, M. \& Spassky, N. Centriole amplification by mother and daughter centrioles differs in multiciliated cells. Nature 516, 104 (2014). 
59. Vladar, E. K. \& Stearns, T. Molecular characterization of centriole assembly in ciliated epithelial cells. J. Cell Biol. 178, 31-42 (2007).

60. Zhao, H. et al. The Cep63 paralogue Deup1 enables massive de novo centriole biogenesis for vertebrate multiciliogenesis. Nat. Cell Biol. 15, 1434 (2013).

61. Higginbotham, H., Bielas, S., Tanaka, T. \& Gleeson J. G. Transgenic mouse line with green-fluorescent protein-labeled Centrin 2 allows visualization of the centrosome in living cells. Transgenic Res. 13, 155-64 (2004).

62. Wong, Y. L. et al. Reversible centriole depletion with an inhibitor of Polo-like kinase 4. Science 348, 1155-1160 (2015).

63. Mitchell, B., Jacobs, R., Li, J., Chien, S. \& Kintner, C. A positive feedback mechanism governs the polarity and motion of motile cilia. Nature 447, 97-101 (2007).

64. Brooks, E. R. \& Wallingford, J. B. Multiciliated Cells. Curr. Biol. 24, R973-R982 (2014).

65. Guirao, B. et al. Coupling between hydrodynamic forces and planar cell polarity orients mammalian motile cilia. Nat. Cell Biol. 12, 341 (2010).

66. Shin, J-B. et al. Xenopus TRPN1 (NOMPC) localizes to microtubule-based cilia in epithelial cells, including inner-ear hair cells. Proc. Natl. Acad. Sci. USA. 102, 1257212577 (2005).

67. Riedel-Kruse, I. H., Hilfinger, A., Howard, J. \& Jülicher, F. How molecular motors shape the flagellar beat. HFSP J. 1, 192-208 (2007).

68. Biggart, E., Pritchard, K., Wilson, R., \& Bush, A. Primary ciliary dyskinesia syndrome associated with abnormal ciliary orientation in infants. Eur. Respir. J. 17, 444-448 (2001).

69. Jorissen, M. \& Willems, T. The secondary nature of ciliary (dis)orientation in secondary and primary ciliary dyskinesia. Acta. Oto-Laryngologica. 124, 527-31 (2004) 
70. Rautiainen, M., Collan, Y., Nuutinen, J. \& Afzelius, B.A. Ciliary orientation in the "immotile cilia" syndrome. Eur. Arch. Otorhinolaryngol. 247, 100-103 (1990).

71. Mönnich, M. et al. Mother Centriole and Regulates TGF- $\beta$ /BMP Signaling at the Primary Cilium," Cell Rep. 22, 2584-2592 (2018).

72. Wojciech, S. et al. The orphan GPR50 receptor promotes constitutive TGF $\beta$ receptor signaling and protects against cancer development. Nat. Commun. 9, 1216 (2018).

73. Silva, M. T., Wensing, L. A., Brum, P. C., Câmara, N. O., Miyabara, E. H. Impaired structural and functional regeneration of skeletal muscles from $\beta 2$-adrenoceptor knockout mice. Acta. Physiol. (Oxf) 211, 617-33 (2014).

74. Donkor, F. F., Mönnich, M., Czirr, E., Hollemann, T. \& Hoyer-Fender, S. Outer dense fibre protein 2 (ODF2) is a self-interacting centrosomal protein with affinity for microtubules. J. Cell Sci. 117, 4643-4651 (2004).

75. Chih, B. et al., A ciliopathy complex at the transition zone protects the cilia as a privileged membrane domain. Nat. Cell Biol. 14, 61 (2012).

76. Garcia-Gonzalo, F. R. et al. A transition zone complex regulates mammalian ciliogenesis and ciliary membrane composition. Nat. Genet. 43, 776 (2011).

77. Kanie, T. et al. The CEP19-RABL2 GTPase Complex Binds IFT-B to Initiate Intraflagellar Transport at the Ciliary Base. Dev. Cell, 42, 22-36 (2017).

78. Mojarad, B. A. et al. CEP19 cooperates with FOP and CEP350 to drive early steps in the ciliogenesis programme. Open Biol. 7, 170114 (2017).

79. Nishijimaa, Y. et al. RABL2 interacts with the intraflagellar transport-B complex and CEP19 and participates in ciliary assembly. Mol. Biol. Cell 28, 1652-1666 (2017). 
80. Lu, C. J. et al. Non-random distribution and sensory functions of primary cilia in vascular smooth muscle cells. Kidney Blood Press. Res. 31, 171-184 (2008).

81. Wu, J. et al. Characterization of Primary Cilia in Human Airway Smooth Muscle Cells. Chest 136, 561-570 (2009).

82. Shah, A. S., Ben-Shahar, Y., Moninger, T. O., Kline, J. N. \& Welsh, M. J. Motile Cilia of Human Airway Epithelia Are Chemosensory. Science 325, 1131-1134 (2009).

83. Teilmann, S. et al. Localization of transient receptor potential ion channels in primary and motile cilia of the female murine reproductive organs. Mol. Reprod. Dev. 71, 444-52 (2005).

84. Carvalho-Santos, Z., Azimzadeh, J., Pereira-Leal, J. B. \& Bettencourt-Dias, M. Tracing the origins of centrioles, cilia, and flagella. J Cell Biol. 194, 165-175 (2011).

85. Bloodgood, R. A. Sensory reception is an attribute of both primary cilia and motile cilia. $J$ Cell Sci. 123, 505-509 (2010).

86. Budi, E. H., Duan, D. \& Derynck, R. Transforming Growth Factor- $\beta$ Receptors and Smads: Regulatory Complexity and Functional Versatility. Trends Cell Biol. 27, 658-672 (2017).

87. Clement, C. A. et al. TGF- $\beta$ signaling is associated with endocytosis at the pocket region of the primary cilium. Cell Rep. 3, 1806-14 (2013) .

88. Tözser, J. et al. TGF- $\beta$ signaling regulates the differentiation of motile cilia. Cell Rep. 11, 1000-1007 (2015).

89. Narayan, K. et al. Multi-resolution correlative focused ion beam scanning electron microscopy: applications to cell biology. J. Struct Biol. 185, 278-284 (2014). 
90. Coyaud, E. et al. BioID-based Identification of Skp Cullin F-box (SCF) $\beta$-TrCP1/2 E3 Ligase Substrates. Mol. Cell Proteomics 14, 1781-95 (2015).

91. Mahjoub, M. R., Xie, Z. \& Stearns, T. Cep120 is asymmetrically localized to the daughter centriole and is essential for centriole assembly. J. Cell Biol. 191, 331-346 (2010).

92. You, Y., Richer, E. J., Huang, T. \& Brody, S. L. Growth and differentiation of mouse tracheal epithelial cells: selection of a proliferative population. Am. J. Physiol. Lung Cell Mol Physiol. 283, L1315-21 (2002). 
Table S1: Radial and axial distance measurements of basal foot proteins in primary cilia $(\mathrm{n}=40)$

838

\begin{tabular}{|l|l|l|}
\hline Protein & Radial distance $(\mathrm{nm})$ & Axial distance $(\mathrm{nm})$ \\
\hline Glut-TUB & $87 \pm 5$ & N/A \\
\hline TCHP & $269 \pm 30$ & $262 \pm 52$ \\
\hline ODF2 CTD & $155 \pm 16$ & $214 \pm 41$ \\
\hline ODF2 MD & $143 \pm 16$ & $209 \pm 45$ \\
\hline CEP128 CTD & $139 \pm 15$ & $239 \pm 70$ \\
\hline GFP-CEP128 & $203 \pm 16$ & $245 \pm 40$ \\
\hline CEP19 & $162 \pm 15$ & $284 \pm 56$ \\
\hline CNTRL CTD & $153 \pm 18$ & $258 \pm 41$ \\
\hline CNTRL MD & $205 \pm 22$ & $248 \pm 52$ \\
\hline GFP-CNTRL & $240 \pm 19$ & $224 \pm 51$ \\
\hline NIN CTD & $248 \pm 16$ & $226 \pm 51$ \\
\hline NIN NTD & $253 \pm 25$ & $238 \pm 32$ \\
\hline CEP170 CTD & $237 \pm 25$ & $230 \pm 62$ \\
\hline CEP170 MD & $231 \pm 22$ & $243 \pm 58$ \\
\hline CEP170 NTD & $244 \pm 22$ & N/A \\
\hline CC2D2A & $198 \pm 20$ & $333 \pm 44$ \\
\hline GAL-3 & $185 \pm 36$ & N/A \\
\hline
\end{tabular}


Table S2: Radial distance measurements of GFP-NIN constructs in ciliated RPE cells ( $\mathrm{n}>23$ )

\begin{tabular}{|l|l|}
\hline NIN constructs & radial distance $(\mathrm{nm})$ \\
\hline GFP-NIN & $245 \pm 25$ \\
\hline GFP-aa197 & $218 \pm 32$ \\
\hline GFP-aa764 & $213 \pm 32$ \\
\hline GFP-aa1640 & $213 \pm 36$ \\
\hline GFP-aa1647 & $201 \pm 32$ \\
\hline
\end{tabular}

Table S3: Radial distance measurements of subdistal appendage proteins in cycling cells $(\mathrm{n}=40)$

867

\begin{tabular}{|l|l|}
\hline protein & radial distance (nm) \\
\hline ODF2 CTD & $137 \pm 16$ \\
\hline CEP128 CTD & $144 \pm 16$ \\
\hline CNTRL CTD & $171 \pm 16$ \\
\hline NIN CTD & $245 \pm 18$ \\
\hline NIN NTD & $243 \pm 25$ \\
\hline CEP170 CTD & $231 \pm 20$ \\
\hline CEP170 MD & $249 \pm 21$ \\
\hline
\end{tabular}

Table S4: Radial distance measurements of basal foot proteins in motile cilia $(n=80)$

\begin{tabular}{|l|l|}
\hline protein & radius distance (nm) \\
\hline ODF2 CTD & $158 \pm 16$ \\
\hline ODF2 MD & $147 \pm 5$ \\
\hline CEP128 CTD & $162 \pm 25$ \\
\hline CEP19 & $177 \pm 22$ \\
\hline CNTRL CTD & $180 \pm 23$ \\
\hline CNTRL MD & $200 \pm 224$ \\
\hline NIN CTD & $188 \pm 29$ \\
\hline NIN NTD & $177 \pm 32$ \\
\hline CEP170 CTD & $191 \pm 30$ \\
\hline CEP170 NTD & $194 \pm 33$ \\
\hline NEDD1 & $197 \pm 41$ \\
\hline Gamma-tub & $206 \pm 33$ \\
\hline
\end{tabular}


Table S5: PCD patients genotype

\begin{tabular}{|l|l|l|}
\hline Name & Gene & Mutation(s) \\
\hline PCD1 & DNAH5 & c.[1432>T]; c[11571-iG $>$ A $]$ \\
\hline PCD2 & DNAH11 & p.[(Cys4286*)];[(Ile4122Ser)] \\
\hline PCD3 & DNHA5 & Hom p.[(Phe634Serfs*2)] \\
\hline
\end{tabular}

Table S6: List of plasmid and primers used in this study

\begin{tabular}{|c|c|c|c|}
\hline $\begin{array}{l}\text { Gene } \\
\text { insert }\end{array}$ & $\begin{array}{c}\text { Vector } \\
\text { backbone }\end{array}$ & Final plasmid & Primer sequences used (5'-3') \\
\hline \multirow{6}{*}{ NIN } & \multirow{6}{*}{$\begin{array}{c}\text { Sept2 } \\
\text { promoter- } \\
\text { FRT puro } \\
\text { endo GFP- } \\
\text { His-Flag }\end{array}$} & $\begin{array}{l}\text { NTD GFP-NIN } \\
\text { (Gibson } \\
\text { Assembly) }\end{array}$ & $\begin{array}{l}\text { NIN: } \\
\text { FOR: 5'-atatcggatccgaattcATGGACGAGGTGGAACAG-3' } \\
\text { REV: 5'-ggtggatccetcgagCTAAGATCTCAGTGGGGG-3' } \\
\text { pcDNA FRT TO: } \\
\text { FOR: 5'-CTCGAGGGATCCACCGGA-3' } \\
\text { REV: 5'-GAATTCGGATCCGATATCAGC-3' }\end{array}$ \\
\hline & & $\begin{array}{l}\text { AfeI GFP-NIN } \\
\quad \text { (aa1647) }\end{array}$ & $\begin{array}{l}\text { FOR: 5'-TCAGAGCGCTCCATGGTGAGCAAGGGCGAG-3' } \\
\text { REV: 5'-CTGAAGCGCTCCTTGTACAGCTCGTCCATGC-3' }\end{array}$ \\
\hline & & $\begin{array}{l}\text { HindIII GFP- } \\
\text { NIN (aa1460) }\end{array}$ & $\begin{array}{l}\text { FOR: 5'-TCAGAAGCTTATGGTGAGCAAGGGCGAG-3' } \\
\text { REV: 5'-CTGAAAGCTTCTTGTACAGCTCGTCCATGC-3' }\end{array}$ \\
\hline & & $\begin{array}{l}\text { XmaI GFP- } \\
\text { NIN (aa197) }\end{array}$ & $\begin{array}{l}\text { FOR: 5'-TCAGCCCGGGTTATGGTGAGCAAGGGCGAG-3', } \\
\text { REV: 5'-CTGACCCGGGACTTGTACAGCTCGTCCATGC-3' }\end{array}$ \\
\hline & & $\begin{array}{l}\text { XmnI GFP- } \\
\text { NIN } \\
\text { (aa764) }\end{array}$ & $\begin{array}{l}\text { FOR: 5'-TCAGGAACAGTTTCTTATGGTGAGCAAGGGCGAG- } \\
\text { 3' } \\
\text { REV: 5'-CTGAGAAACTGTTCCTTGTACAGCTCGTCCATGC- } \\
\text { 3' }\end{array}$ \\
\hline & & $\begin{array}{l}\text { GFP-NIN with } \\
\text { stop codon after } \\
\text { GFP }\end{array}$ & $\begin{array}{l}\text { FOR: 5'-GACGAGCTGTACAAGTAATCCGGACTCAGATCTG- } \\
\text { 3' } \\
\text { REV: 5'-CAGATCTGAGTCCGGATTACTTGTACAGCTCGTC- } \\
\text { 3' }\end{array}$ \\
\hline
\end{tabular}




\begin{tabular}{|c|c|c|c|}
\hline CNTRL & $\begin{array}{c}\text { Sept2 } \\
\text { promoter- } \\
\text { FRT puro } \\
\text { endo GFP- } \\
\text { His-Flag }\end{array}$ & $\begin{array}{c}\text { NTD } \\
\text { GFP- } \\
\text { CNTRL } \\
\text { (Gibson } \\
\text { assembly) }\end{array}$ & $\begin{array}{l}\text { CNTRL: } \\
\text { FOR: } \\
\text { 5', atatcggatccgaattcATGAAGAAAGGTTCTCAACAAAAAATATTC- } \\
\text { 3' } \\
\text { REV: } \\
\text { 5'-ggtggatccetcgagTCATCTGGCTGAGGCATTC-3' } \\
\text { pcDNA FRT TO: } \\
\text { FOR: 5'-CTCGAGGGATCCACCGGA-3' } \\
\text { REV: 5'-GAATTCGGATCCGATATCAGC-3' }\end{array}$ \\
\hline \multirow{2}{*}{ CEP128 } & $\begin{array}{c}\text { CMV } \\
\text { promoter- } \\
\text { pcDNA5- } \\
\text { FRT-TO- } \\
\text { Flag-BIRA* }\end{array}$ & $\begin{array}{l}\text { CEP128- } \\
\text { Flag- } \\
\text { BIRA* }\end{array}$ & $\begin{array}{l}\text { FOR (HindIII site): } \\
\text { 5'-TCAGAAGCTTAGCATGGCCGAGAGCAGCAGC-3' } \\
\text { REV (KpnI site): } \\
\text { 5'-CTGAGGTACCCGCTGCCGTATTCCTCTTTC-3' }\end{array}$ \\
\hline & $\begin{array}{l}\text { CMV } \\
\text { promoter- } \\
\text { pDEST-TO- } \\
\text { GFP-FRT }\end{array}$ & $\begin{array}{c}\text { GFP- } \\
\text { CEP128 }\end{array}$ & Gift from Pelletier Lab \\
\hline
\end{tabular}

Table S7: List of antibodies used in this study

890 Note: CTD-recognizing antibodies were used at default in case of multiple antibodies for the 891 same protein, unless mentioned otherwise.

892

\begin{tabular}{|c|c|c|c|c|c|c|}
\hline Gene & $\begin{array}{c}\text { Domain } \\
\text { recognized }\end{array}$ & Source & Catalog \# & Species & Dilution & $\begin{array}{c}\text { Fixation } \\
\text { method }\end{array}$ \\
\hline \multirow{2}{*}{ CEP128 } & $\begin{array}{c}\text { CTD (aa 1044- } \\
1094)\end{array}$ & Abcam & Ab11879 & rabbit & $1: 50$ & methanol \\
\hline \multirow{2}{*}{ ODF2 } & $\begin{array}{c}\text { CTD (aa 750-C- } \\
\text { terminus) }\end{array}$ & Abcam & Ab43840 & rabbit & $1: 500$ & methanol \\
\cline { 2 - 7 } & $\begin{array}{c}\text { NTD 250-632 } \\
\text { (hCenexin1) }\end{array}$ & Kyung Lee Lab & - & rabbit & $1: 50$ & methanol \\
\hline
\end{tabular}




\begin{tabular}{|c|c|c|c|c|c|c|}
\hline & $\begin{array}{c}\text { aa } 255-618 \\
\text { (hOdf2) }\end{array}$ & & & & & \\
\hline CEP19 & aa $1-163$ & Proteintech & 26036-1-AP & rabbit & $1: 50$ & methanol \\
\hline \multirow{4}{*}{ CNTRL } & $\begin{array}{l}\text { CTD (aa 2026- } \\
\text { 2325) (for STORM } \\
\text { experiment) }\end{array}$ & Santa Cruz & sc-135020 & rabbit & $1: 50$ & methanol \\
\hline & $\begin{array}{c}\text { CTD (aa 2187- } \\
2291)\end{array}$ & Atlas Antibodies & HPA020468 & rabbit & $1: 50$ & $\begin{array}{c}\text { methanol } \\
\text { or PFA }\end{array}$ \\
\hline & $\begin{array}{c}\text { CTD (aa 2026- } \\
2325)\end{array}$ & Santa Cruz & sc365521 & mouse & $1: 50$ & methanol \\
\hline & $\begin{array}{c}\text { MD (aa 1063- } \\
1168)\end{array}$ & Atlas Antibodies & HPA051583 & rabbit & $1: 25$ & methanol \\
\hline \multirow{3}{*}{$N I N$} & $\begin{array}{c}\text { CTD (aa 1870- } \\
2020)\end{array}$ & Proteintech & 13007-1-AP & rabbit & $1: 500$ & methanol \\
\hline & NTD (L77) & $\begin{array}{l}\text { Michael Bornens } \\
\text { Lab }\end{array}$ & - & rabbit & $1: 10,000$ & methanol \\
\hline & $\begin{array}{l}\text { NTD (in SDA } \\
\text { measurements) }\end{array}$ & Santa Cruz & $\begin{array}{c}\text { sc-5014 (Y- } \\
16)\end{array}$ & goat & $1: 50$ & methanol \\
\hline \multirow{3}{*}{ CEP170 } & $\begin{array}{l}\text { CTD (aa 1534-C- } \\
\text { terminus) }\end{array}$ & Abcam & $\mathrm{Ab} 7250$ & rabbit & $1: 200$ & methanol \\
\hline & $\begin{array}{c}\text { MD (aa 1010- } \\
1200)\end{array}$ & $\begin{array}{c}\text { Iain Cheeseman } \\
\text { Lab }\end{array}$ & - & rabbit & $1: 1000$ & methanol \\
\hline & NTD & Thermo Fisher & $41-3200$ & mouse & 1:200 & methanol \\
\hline CCDC120 & aa $150-250$ & Atlas Antibodies & HPA000561 & rabbit & $1: 50$ & methanol \\
\hline CCDC68 & aa $165-247$ & Atlas Antibodies & HPA048197 & rabbit & $1: 50$ & methanol \\
\hline GAL3 & - & Elsasser Lab & - & rabbit & $1: 100$ & methanol \\
\hline$C C 2 D 2 A$ & - & Proteintech & 22293-1-AP & rabbit & $1: 50$ & methanol \\
\hline \multirow{2}{*}{ CEP112 } & CTD (aa 607-955) & Proteintech & 24928-1-AP & rabbit & $1: 100$ & methanol \\
\hline & MD (aa361-427) & Atlas antibodies & HPA024481 & rabbit & $1: 50$ & $\begin{array}{c}\text { methanol } \\
\text { or PFA }\end{array}$ \\
\hline \multirow{2}{*}{ POCIB } & aa $321-350$ & Invitrogen & PA5-24495 & rabbit & $1: 50$ & methanol \\
\hline & - & $\begin{array}{l}\text { Tomer Avidor- } \\
\text { Reiss Lab }\end{array}$ & - & rat & $1: 50$ & methanol \\
\hline
\end{tabular}




\begin{tabular}{|c|c|c|c|c|c|c|}
\hline $\begin{array}{l}\text { Polyglutamylation } \\
\text { Modification }\end{array}$ & - & Adipogen & $\begin{array}{l}\text { AG-20B- } \\
0020-C 1 \\
\text { (GT335) }\end{array}$ & mouse & $1: 1000$ & methanol \\
\hline $\begin{array}{l}\text { TUBA4A ( } \alpha- \\
\text { tubulin) }\end{array}$ & - & Sigma-Aldrich & $\begin{array}{c}\text { T9026 } \\
\text { (DM1A) }\end{array}$ & mouse & $1: 500$ & $\begin{array}{c}\text { methanol } \\
\text { or PFA }\end{array}$ \\
\hline $\begin{array}{c}\text { TUBA4A }(\alpha- \\
\text { tubulin- FITC } \\
\text { conjugated }\end{array}$ & - & Sigma-Aldrich & $\begin{array}{c}\text { F2168 } \\
(\mathrm{DM} 1 \mathrm{~A})\end{array}$ & mouse & $1: 500$ & $\begin{array}{c}\text { methanol } \\
\text { or PFA }\end{array}$ \\
\hline SAS6 & - & Santa Cruz & sc- 82360 & mouse & $1: 200$ & methanol \\
\hline TCHP & aa $261-335$ & Atlas Antibodies & HPA038638 & rabbit & $1: 50$ & methanol \\
\hline$G F P$ & full-length & Abcam & Ab13970 & chicken & $1: 2000$ & methanol \\
\hline Turbo GFP & full-length & Thermo Fisher & PA5-22688 & rabbit & $1: 500$ & PFA \\
\hline NEDDI & & Abcam & 57336 & mouse & $1: 500$ & methanol \\
\hline$\gamma$-tubulin & & Sigma & T6557 & mouse & $1: 500$ & methanol \\
\hline RPGRIP1L & & Proteintech & 55160-1-AP & rabbit & $1: 50$ & methanol \\
\hline RSPH4A & & Atlas Antibodies & HPA031196 & rabbit & $1: 50$ & methanol \\
\hline GAS8 & & Atlas Antibodies & HPA041311 & rabbit & $1: 50$ & methanol \\
\hline CEP120 & & $\begin{array}{l}\text { Moe Mahjoub } \\
\text { Lab }\end{array}$ & $\begin{array}{l}\text { Mahjoub et al. } \\
\text { JCB } 2010\end{array}$ & rabbit & $1: 10000$ & methanol \\
\hline CEP164 & - & $\begin{array}{c}\text { Novus } \\
\text { Biologicals }\end{array}$ & 45330002 & rabbit & $1: 500$ & methanol \\
\hline $\begin{array}{l}\text { acetylated } \alpha- \\
\text { tubulin }\end{array}$ & & Sigma & $\mathrm{T} 7451$ & mouse & $1: 50$ & methanol \\
\hline$Z O-1$ & & Santa Cruz & sc-33725 & rat & $1: 1000$ & methanol \\
\hline $\begin{array}{c}\text { phospho-TGFbeta } \\
\text { RI (S165) }\end{array}$ & aa $131-180$ & Abcam & ab112095 & rabbit & $1: 50$ & PFA \\
\hline
\end{tabular}

893 